\title{
Huntington Disease as a Neurodevelopmental Disorder and Early Signs of the Disease in Stem Cells
}

\author{
Kalina Wiatr $^{1}$ - Wojciech J. Szlachcic ${ }^{1}$ - Marta Trzeciak $^{1}$ - Marek Figlerowicz ${ }^{1}$. \\ Maciej Figiel $^{1}$
}

Received: 5 January 2017 / Accepted: 1 March 2017 /Published online: 11 May 2017

(C) The Author(s) 2017. This article is an open access publication

\begin{abstract}
Huntington disease (HD) is a dominantly inherited disorder caused by a CAG expansion mutation in the huntingtin (HTT) gene, which results in the HTT protein that contains an expanded polyglutamine tract. The adult form of HD exhibits a late onset of the fully symptomatic phase. However, there is also a long presymptomatic phase, which has been increasingly investigated and recognized as important for the disease development. Moreover, the juvenile form of HD, evoked by a higher number of CAG repeats, resembles a neurodevelopmental disorder and has recently been the focus of additional interest. Multiple lines of data, such as the developmental necessity of HTT, its role in the cell cycle and neurogenesis, and findings from pluripotent stem cells, suggest the existence of a neurodevelopmental component in HD pathogenesis. Therefore, we discuss the early molecular pathogenesis of HD in pluripotent and neural stem cells, with respect to the neurodevelopmental aspects of HD.
\end{abstract}

Keywords Stem cells $\cdot$ Polyglutamine diseases $\cdot$ ESC $\cdot$ iPS . iPSC $\cdot$ NSC $\cdot$ Neurodegenerative disease .

Neurodevelopmental disease $\cdot$ polyQ disease $\cdot$ Huntington disease

Electronic supplementary material The online version of this article (doi:10.1007/s12035-017-0477-7) contains supplementary material, which is available to authorized users.

Maciej Figiel

mfigiel@ibch.poznan.pl

1 Institute of Bioorganic Chemistry, Polish Academy of Sciences, Noskowskiego 12/14, 61-704 Poznan, Poland

\section{Introduction}

The onset of serious motor and cognitive symptoms is late in Huntington disease (HD). However, extensive longitudinal research in the PREDICT-HD [1] and other clinical programs [2] indicates that premanifest HD patients develop subtle HDmediated changes decades before classical diagnosis. These changes include cognitive, functional, and psychiatric symptoms; altered brain morphology and connectivity; and even subtle motor deficits [3-8]. Moreover, neuronal degeneration and the deregulation of neurodevelopmental genes occur long before the onset of classical HD symptoms and phenotypic changes in both mouse models and patients [9-14]. These findings raise the question of whether premanifest symptoms in $\mathrm{HD}$ are a consequence of neurodevelopmental abnormalities. Neurodevelopmental deficits typically occur in childhood. For instance, children at risk of HD exhibit smaller head size, indicating a deficit in brain growth [15]. In addition, lower body weight index (BMI) is also present in prodromal HD children and body weight deficit was identified for juvenile HD suggesting a developmental deficit probably due to mitochondrial dysfunction [16]. The HD juvenile form, also known as "Westphal variant," is characterized by a high number of CAG repeats, onset under 20 years of age, and disease manifestation different than that of adult-onset disease [17, 18].

Multiple roles have been established for normal and mutant huntingtin (HTT) in pre- and postnatal development via in vivo and in vitro developmental research on animal models. Evidence from recent stem cell studies supports the idea that mutant HTT-dependent changes may be detected early, even at the naïve pluripotent cell stage (see discussion and references in the following sections). Therefore, it is important to elucidate the pathogenesis of $\mathrm{HD}$ along the differentiation axis (pluripotent stem cells (PSC) $\rightarrow$ neural stem cells (NSC) $\rightarrow$ mature neurons, Fig. 1) to identify the early processes relevant to developmental defects and disease onset. Understanding 
Fig. 1 HD pathogenic changes occur along the differentiation axis: pluripotent stem cells $\rightarrow$ $\mathrm{NSC} \rightarrow$ mature neurons. The figure summarizes HD pathogenesis in the indicated cell types. Many HD-associated changes are present in the early stages of development, beginning with pluripotent stem cells and continuing throughout differentiation to NSC and mature neurons. The data form high-throughput transcriptomics and proteomics were not included in the table. Changes detected (orange), absence of change (green), discrepant results (gray), data non-available $(N / A)$, and non-applicable $(X)$ (Color figure online)

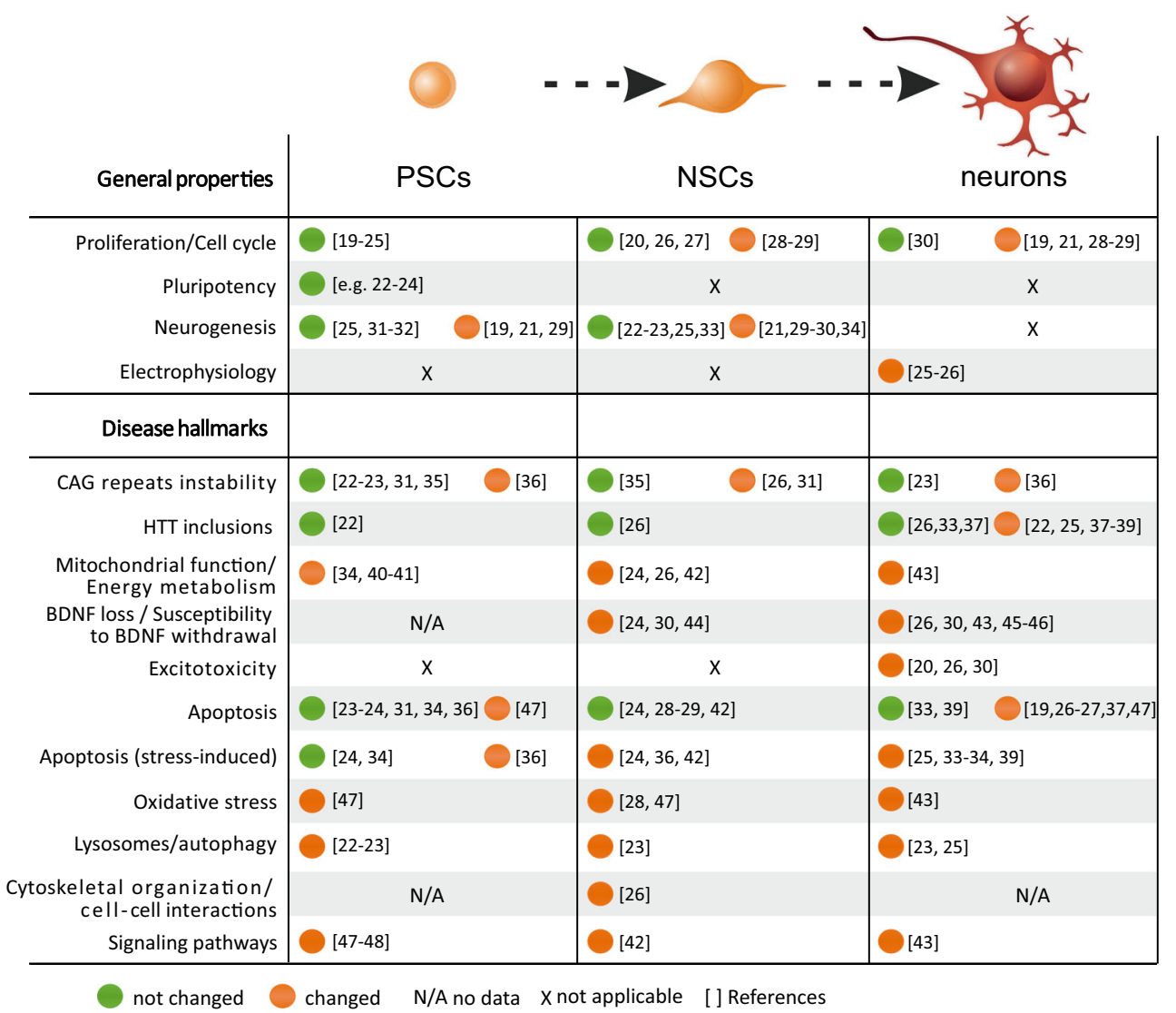

the pathogenesis in these cell types is particularly important for the development of effective cell therapies and determination of the therapeutic impact.

The aim of this work is to review the current knowledge regarding the most important facts about the role of normal and mutant HTT in organism development. Subsequently, we will discuss early molecular pathogenesis of HD identified in PSC and NSC, which may underlie the developmental deficits in HD. Additionally, we have performed a meta-analysis to determine whether previously identified deregulated genes/ proteins in HD PSC, NSC, and neurons are related to developmental Gene Ontology (GO) terms.

\section{HTT Is Necessary for Development}

HTT is crucial for the organism development (Fig. 2), and the absence of HTT is lethal in mice around developmental day E7.5-8.5 [49-51]. This lethality may be caused by early embryonic patterning deficits, including shortened primitive streak and lack of headfolds, which denote a failure in the development of the head [52]. The expression of wild-type HTT at approximately $10-15 \%$ of normal levels may rescue this embryonic lethality; however, the HTT insufficiency causes abnormal brain development and mild movement abnormalities [53]. On the other hand, similar low levels of mutant Q50 or Q100 HTT lead to perinatal death [53, 54]. The discrepancy in the effects of low levels of wild-type vs mutant HTT may result from both the loss of function of mutant HTT during development and/or the protective role of normal HTT, interfering with the gain of function of mutant HTT. The decreased level of wild-type HTT (10-15\% of normal levels) in mouse embryos, followed by reconstitution of HTT expression to normal level on postnatal day 21, resulted in progressive striatal and cortical neuronal degeneration and motor incoordination later in life [55]. In addition, when mice are exposed to normal levels of mutant HTT 97Q until postnatal day 21 , they develop a HD-like phenotype including neuropathology and motor deficits. The phenotype is not as severe as in the mice with lifelong expression of HTT 97Q [56]. Summarizing, low level of HTT or expression of mutant HTT, limited to the time of embryonic development and short postnatal time when striatal neurogenesis occurs, is sufficient for generation of the neurological phenotype in mice. In addition, the conditional reduction of HTT in the mouse forebrain, which is initiated at later embryonic stages and reached $84 \%$ reduction of expression by postnatal day 60 , leads to progressive neurodegeneration and premature death [57]. In addition, the phenomenon called "huntingtin holiday" also suggests that the disease symptoms in HD may be reversed but the reversal is not complete [58]. HTT knockout (KO) in Wnt1- 


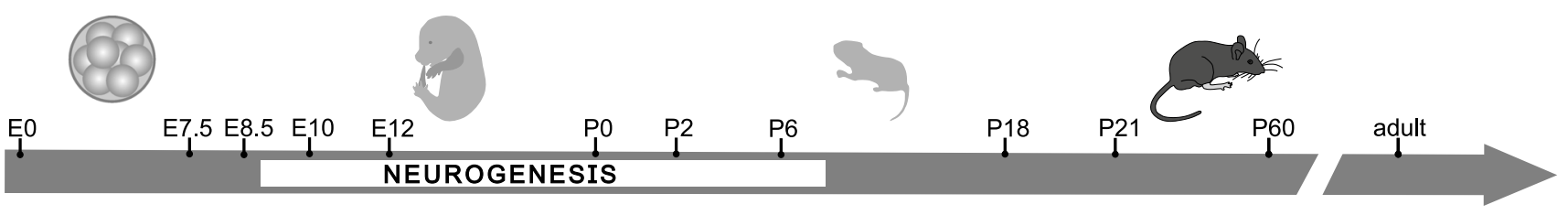

wt $\mathrm{Htt}^{+++}$or wt $\mathrm{Htt+l-}$

normal phenotype

\begin{tabular}{|c|c|c|c|}
\hline wt $\mathrm{Htt}^{+/+}$ & normal phenotype & in forebrain or Nestin+ cells & wt $\mathrm{Htt}^{-1}$ \\
\hline wt $\mathrm{Htt}^{+/+}$ & non-CNS defects & in all tissues & wt Htt ${ }^{-1-}$ \\
\hline $\mathrm{mHtt}$ Q97/- & HD-like phenotype & $\mathrm{mHtt}^{-1-}$ & \\
\hline
\end{tabular}

\section{Legend}

normal Htt expression
Fig. 2 Phenotypic effects of the HTT gene manipulation during mouse development. The diagram illustrates the knockout and knockdown of normal and mutant HTT, at several points in time of mouse embryonic and postnatal development, indicating CNS and non-CNS consequences. The mouse age and the duration of HTT knockout (red bars) or knockdown (orange bars) in mouse life are indicated by the relevant length of bars. Green indicates non-manipulated, wild-type HTT

expressing cells of the midbrain, hindbrain, and cerebellar granule cells results in hydrocephaly and death at postnatal P6-18 [60]. In contrast, mice remained unaffected when HTT was knocked down in the forebrain or Nestin-positive cells at 2, 4, or 8 months of age [55]. HTT knockdown to the level hardly identified by immunoblotting in all mouse tissues at 2 months of age leads to death as a result of non-CNS defects, such as acute pancreatitis [59]. However, no neuronal deficits were identified in these mice. In addition, the deletion of polyglutamine (polyQ) or proline-rich regions within the $\mathrm{N}$ terminus of HTT did not affect normal mouse development, whereas the $\mathrm{N}$-terminus alone is insufficient to rescue lethality in embryonic and young mice [61-63].

\section{Developmental Functions of HTT}

The neural rosettes are radial arrangements of cells in the culture, indicating that embryonic stem cells (ESC) differentiate and form NSC. Therefore, neural rosettes in culture are a developmental marker resembling the radial arrangements of NSC forming neural tube during development [64]. Mouse ESC-derived NSC with low expression of HTT are able to form rosettes; however, NSC which are deprived of HTT (HTT-null cells) are unable to form expression. Premature death or embryonic death is indicated by a shorter bar, ending with a gray-colored gradient. The phenotypic effects of the mutant and WT HTT gene manipulation are described directly on the bars. The mutant and WT HTT gene manipulation is indicated as genotype for each experiment at the beginning of each segment of the bar (Color figure online)

neural rosettes in vitro [65]. The phenotype, which is referred to as rosetteless, is reflected in the impaired acquisition of proper polarity during neurulation in HTT-null zebrafish embryogenesis [65]. It is a consequence of defective cell adhesion function of HTT, which depends on the N-terminal portion of the HTT protein, and is mediated by ADAM10/N-cadherin [65]. The cell adhesion function of N-terminus of HTT is a recent evolutionary step which probably enabled more complex development of the CNS [65].

HTT is essential for the formation and orientation of a proper mitotic spindle [66]. Its depletion during embryonic cortical neurogenesis by in utero electroporation, using HTT siRNA, causes incorrect spindle orientation, which results in a decreased pool of proliferating progenitors and increased differentiation due to an imbalance in symmetric vs asymmetric divisions [66, 67]. Similarly, the expression of mutant HTT in the absence of normal HTT in cells derived from $\mathrm{Hdh}^{\mathrm{Q} 111 / \mathrm{Q} 111}$ mice causes mitotic spindle misorientation along with defects in the proliferation of neuroprogenitors [68].

Conditional reduction of HTT (less than $10 \%$ of the normal level), occurring selectively in cortical excitatory Emx1expressing neurons, produces low HTT expression already at E 9.5, prior to early postnatal synaptic development. Notably, 
the depletion also includes cortical layer 5, which projects to the striatum. Such experimental setup demonstrated altered cortical and corticostriatal connectivity and the increase in excitatory synapse formation in the striatum, which suggests a non-cell-autonomous effect on maturation of striatal medium spiny neurons (MSNs) [69]. Similar changes have been identified in the corticostriatal development of HD knock-in zQ175 mice, which suggests HTT loss of function in the development of corticostriatal synaptic connectivity [69]. Aberrant cortical inputs may affect the proper maturation of striatal MSNs, since generation of striatal neural progenitors (NPC) is also compromised in HdhQ111 knock-in mice [70] and patients [71]. Abnormal specification and maturation of MSNs impair the acquisition of the proper mature striatal cytoarchitecture. Improperly matured MSNs may be vulnerable to stress-mediated cell death in the symptomatic stages of the disease. The overall evidence indicates a neurodevelopmental stage in $\mathrm{HD}$ and its significant role in the disease development.

\section{Considerations for HD Modeling in PSC and NSC}

The earliest molecular phenotypes of HD pathology were identified in pluripotent stem cellular models. PSC recapitulate the cellular stages occurring during early stages of organism development. ESC are isolated from inner cell mass of the blastocysts, whereas the induced pluripotent stem cells (iPSC) are produced by cellular reprogramming of somatic cells, with the use of genetic mechanism described by Takahashi and Yamanaka [72]. Table 1 summarizes and provides an overview of the existing animal and HD patient stem cell models. This overview indicates that the existing HD stem cells possess highly variable characteristics, such as technology (derivation method, cell source, and epigenetic status), disease (number of CAG repeats), and experimental design (e.g., the number of lines directly compared in order to determine the phenotypes, and the lines compared had uniform or differing genetic backgrounds, i.e., isogenic or non-isogenic/mutation silenced/ corrected). For example, the majority of HD patient iPSC were produced using stable genomic integration of reprogramming factors, which remain in iPSC genome after the reprogramming process and may affect the observed HD changes. In contrast, the newest techniques use the reprogramming systems which involve significant control over the expression of exogenous reprogramming factors and prevent integration of these factors with the genome of somatic cells during the reprogramming process. Such systems, e.g., based on Sendai virus, messenger RNA (mRNA), or episomal vectors, are denoted as integration free [73]. In addition, for identification of the phenotypes, iPSC from HD patients were compared to iPSC from other, genetically unrelated, nonaffected patients. This type of comparison is characterized by a limited resolution due to genetic modifiers, which may affect phenotypes. For example, the CAG tract length in HTT is not entirely correlative with the disease onset and duration, pointing to the existence of additional genetic modifiers [91, 92]. HD phenotypes can also be modified by the epigenome states of iPSC, which may convey transcriptional characteristics of source somatic cells. Importantly, the epigenome states in iPSC are related to different types of pluripotency, namely primed and naïve pluripotency [93]. The currently available human iPSCs commonly occur as primed pluripotent cells, and such cell state first appears in later blastocyst stages [94]. Naïve pluripotent state is characteristic of cells of the inner cell mass of the early blastocyst, and such stage is typical of mouse ESC and iPSC. Naïve pluripotent cells self-renew rapidly and almost indefinitely in vitro, and their self-renewal is dependent on the leukemia inhibitory factor (LIF) [93]. An epigenetic state of both naïve and primed iPSC may be recognized by the methylation status of their genome. Naïve PSC have transcriptionally active hypomethylated genome, while the primed PSC already exhibit some methylation patterns characteristic of more advanced stage of the cell linage [93]. The available protocols for generation of human iPSC can be used to reprogram somatic cells until primed stage but are not suitable for direct reprogramming to developmentally earlier, naïve cell stage characterized by fewer epigenetic marks. Therefore, the genome of primed human iPSC exhibits remaining epigenetic marks of source cells and additionally acquires new epigenetic marks by reprogramming or continuous culture $[95,96]$. Such epigenetic marks can affect the differentiation potential and development of HD phenotypes [80].

One potential solution to overcome variability in determining HD phenotypes is to increase the statistical power by increasing the number of patients and iPSC lines. However, the best solution is to employ genetic technologies, such as genome editing or constant short hairpin RNA (shRNA) expression, to generate corrected, patient-specific isogenic cells suitable for use as control cell lines. A complementary solution is to use the iPSC from healthy patients, to generate the isogenic iPSC with incorporated mutant genes. Therefore, the current knowledge of HD-mediated changes will have to be verified using more technologically advanced stem cell systems.

NSC are multipotent, self-renewing cells that differentiate into neural, glial, and oligodendrocyte lineages and represent the next stage of differentiation in the process of nervous system development. In the adult mammalian brain, NSC contribute to the brain plasticity and are located in the dentate gyrus of the hippocampus and the telencephalic subventricular zone [98]. During postembryonic and embryonic neurogenesis, NSC undergo symmetric and asymmetric divisions to generate NPC, which are unipotent or oligopotent; thus, they have a limited ability to self-renew and are committed to neural fate. Both NSC and NPC require growth factors and extracellular signals to regulate proliferation and differentiation. NSC may be maintained in vitro, in multiple, distinct 
Table 1 Pluripotent models of HD

\begin{tabular}{|c|c|c|c|c|c|}
\hline $\begin{array}{l}\text { Species and } \\
\text { cell type }\end{array}$ & Name (mutQ number) & Model/cells of origin & Derivation method (factors) & Isogenic & References \\
\hline \multirow[t]{5}{*}{ Mouse ESC } & Hdh CAG150 (150) & Hdh CAG150 knock-in & Embryo & Syngeneic & [19] \\
\hline & $\begin{array}{l}H d h^{Q 20 / 7}(20) \\
H d h^{Q 50 / 7}(50) \\
H d h^{Q 91 / 7}(91) \\
H d h^{Q 111 / 7}(111)\end{array}$ & 129Sv mES & Knock-in & Yes & $\begin{array}{l}{[40][21,27,29,} \\
32]\end{array}$ \\
\hline & $H t t^{F 140 Q / 7 Q}$ & $\mathrm{mES}$ & Knock-in & Yes & {$[28]$} \\
\hline & HD ESC (127) & R6/1-HTTex1 & Embryo & Syngeneic & {$[36]$} \\
\hline & $\begin{array}{l}H d h^{Q 20 / 7}(20) \\
H d h^{Q 140 / 7}(140)\end{array}$ & CAG140 knock-in & $\mathrm{N} / \mathrm{d}$ & Syngeneic & {$[27,41]$} \\
\hline \multirow[t]{2}{*}{ Monkey ESC } & TrES1 (72) [tetraploid] & $\begin{array}{l}\text { rHD-HTTex1-GFP } \\
\text { fibroblasts/WT oocyte }\end{array}$ & Hybrid embryo & No & [73] \\
\hline & rHD-ES-7x (28-48, one line 131) & rHD-HTTex1-GFP & Embryo & No & {$[39,74]$} \\
\hline \multirow[t]{8}{*}{ Human ESC } & $\begin{array}{l}\text { hESC-184 } \\
\text { hESC-196 }\end{array}$ & $\mathrm{IVF} / \mathrm{PGD}^{\mathrm{b}}$ & Embryo & No & {$[75,76]$} \\
\hline & VUB05_HD (44) & IVF/PGD ${ }^{\mathrm{b}}$ & Embryo & No & {$[35,76,77,78]$} \\
\hline & $\begin{array}{l}\text { SI-186 (37) } \\
\text { SI-187(51) }\end{array}$ & $\mathrm{IVF} / \mathrm{PGD}^{\mathrm{b}}$ & Embryo & No & {$[31]$} \\
\hline & STR-155-HD (44) a.k.a. Huez2.3 & IVF/PGD ${ }^{\mathrm{b}}$ & Embryo & No & {$[79,76,78]$} \\
\hline & $\begin{array}{l}\text { SIVF017-HD (40) } \\
\text { SIVF018-HD (46) } \\
\text { SIVF020-HD (48) } \\
\text { SIVF046-HD (45) } \\
\text { a.k.a. GENEA017,18,20,46 }\end{array}$ & $\mathrm{IVF} / \mathrm{PGD}^{\mathrm{b}}$ & Embryo & No & {$[80,34,76]$} \\
\hline & $\begin{array}{l}\text { Q23 (23) } \\
\text { Q73 (73) } \\
\text { Q145 (145) }\end{array}$ & H9 hESC & $\begin{array}{l}\text { piggyBAC transposon w/ } \\
\text { HTTex } 1 \text { cDNA }\end{array}$ & Yes & {$[37]$} \\
\hline & $\begin{array}{l}\text { GENEA089 }(41) \\
\text { GENEA090 }(46)\end{array}$ & $\mathrm{IVF} / \mathrm{PGD}^{\mathrm{b}}$ & Embryo & No & [34] \\
\hline & $\begin{array}{l}\text { GENEA091 (42) } \\
\text { KCL027 (43) } \\
\text { KCL028 (43) } \\
\text { KCL036 (38) }\end{array}$ & $\mathrm{IVF} / \mathrm{PGD}^{\mathrm{b}}$ & Embryo & No & {$[81]$} \\
\hline \multirow[t]{2}{*}{ Mouse iPSC } & HD-iPS (two mice) (144) & $\begin{array}{l}\text { R6/2-HTTex } 1 \text { transgenic } \\
\text { fibroblasts }\end{array}$ & Retroviral (OSKM) & Syngeneic & {$[22]$} \\
\hline & YAC-HD-iPS (128) & $\begin{array}{l}\text { YAC128 transgenic } \\
\text { fibroblasts }\end{array}$ & $\begin{array}{l}\text { piggyBac (OSKML), excised } \\
\text { from genome }\end{array}$ & Syngeneic & {$[48]$} \\
\hline \multirow[t]{2}{*}{ Monkey iPSC } & $\begin{array}{l}\text { RiPS-3 }(72) \\
+3 \text { other }\end{array}$ & rHD-HTTex1-GFP fibroblasts & Retroviral (OSK) & No & {$[82]$} \\
\hline & HD-14 (27/65) & $\begin{array}{l}\text { rHD-HTTex1-GFP dental } \\
\text { pulp stromal cells }\end{array}$ & Retroviral (OSK) & No & [39] \\
\hline \multirow[t]{7}{*}{ Human iPSC } & $\begin{array}{l}\text { HD-iPS-4 (GM23225) and HD2 } \\
\quad \text { (72) }\end{array}$ & $\begin{array}{l}\text { Fibroblasts: } \\
\text { GM04281 }\end{array}$ & Retroviral (OSKM) & No & $\begin{array}{l}{[83][24,38,42,} \\
\quad 44,47,84]\end{array}$ \\
\hline & $\begin{array}{l}\text { Corrected-HD-iPS4 clones C127 } \\
\text { (21) and C116 (20) }\end{array}$ & HD-iPS4 (72) line & Homologous recombination & Yes & {$[42]$} \\
\hline & $\begin{array}{l}\mathrm{HD}^{-i \mathrm{PS}^{\mathrm{HOM}}} 4 \mathrm{~F} / 3 \mathrm{~F}(42 / 44)^{\mathrm{c}} \\
\mathrm{HD}^{\mathrm{H}} \mathrm{PS}^{\mathrm{HOM}} 4 \mathrm{~F}(39 / 43)^{\mathrm{c}} \\
\mathrm{HD}^{\mathrm{iPS}}{ }^{\mathrm{HET}} 3 \mathrm{~F}(45)\end{array}$ & $\begin{array}{l}\text { Fibroblasts: } \\
\text { HD509 } \\
\text { HD832 } \\
\text { HD1657 }\end{array}$ & Lentiviral (OSKM/OSK) & No & {$[23]$} \\
\hline & $\begin{array}{l}\text { F-HD-iPSC (50) } \\
\text { D-HD-iPSC (109) }\end{array}$ & Fibroblasts & Retroviral (OSKM) & No & {$[85]$} \\
\hline & $\begin{array}{l}\text { HD60i (60) } \\
\text { HD109i.1 (109) } \\
\text { HD180i (180) }\end{array}$ & $\begin{array}{l}\text { Fibroblasts: } \\
\text { GM03621 } \\
\text { ND39258 } \\
\text { GM09197 }\end{array}$ & $\begin{array}{l}\text { Lentiviral (OSKMNL) } \\
\text { Retroviral (OSKM) }\end{array}$ & No & {$[26]$} \\
\hline & $\begin{array}{l}\text { HD1-5x (n/d) } \\
\text { HD2-5x (86Q) }\end{array}$ & $\begin{array}{l}\text { Fibroblasts: } \\
\text { GM04693 } \\
\text { GM05539 }\end{array}$ & Lentiviral (OSKM) & No & [43] \\
\hline & $\begin{array}{l}\operatorname{HD} 70(70) \\
\text { HD180 (180) }\end{array}$ & $\begin{array}{l}\text { Fibroblasts: } \\
\text { GM21756 GM09197 }\end{array}$ & Episomal (OSKML+sh-p53) & No & {$[86,87]$} \\
\hline
\end{tabular}


Table 1 (continued)

\begin{tabular}{|c|c|c|c|c|c|}
\hline $\begin{array}{l}\text { Species and } \\
\text { cell type }\end{array}$ & Name (mutQ number) & Model/cells of origin & Derivation method (factors) & Isogenic & References \\
\hline & HD60n (60) & Fibroblasts: & \multirow[t]{4}{*}{ Episomal (OSKML+sh-p53) } & \multirow[t]{4}{*}{ No } & \multirow[t]{4}{*}[30]{} \\
\hline & HD109n (109) & GM09197 & & & \\
\hline & HD180n (180) & ND39258 & & & \\
\hline & & GM03621 & & & \\
\hline & ND4228, ND4229, ND4230 (71) & Fibroblasts: & \multirow[t]{2}{*}{ Episomal (OSKML+sh-p53) } & \multirow[t]{2}{*}{ No } & \multirow[t]{2}{*}{ NINDS $^{\mathrm{a}}[48]$} \\
\hline & ND4222, ND4223, ND4224 (109) & GM04281 & & & \\
\hline & ND41657 (57) & $\begin{array}{l}\text { Fibroblasts: } \\
\text { ND33392 }\end{array}$ & Episomal (OSKML +sh-p53) & No & $\operatorname{NINDS}^{\mathrm{a}}[88,89]$ \\
\hline & HD-iPSC-A1, -A7 (43) & \multirow[t]{2}{*}{ Fibroblasts } & \multirow[t]{2}{*}{ Retroviral (OSKMN) } & \multirow[t]{2}{*}{ No } & \multirow[t]{2}{*}[33]{} \\
\hline & HD-iPSC-B4, -B16 (43) & & & & \\
\hline & Q47 (47) & \multirow[t]{2}{*}{ Fibroblasts } & \multirow[t]{2}{*}{ Lentiviral (OSKM) } & \multirow[t]{2}{*}{ No } & \multirow[t]{2}{*}{ [46] } \\
\hline & Q70 (70) & & & & \\
\hline & iPSHD11 (40) & \multirow[t]{3}{*}{ Fibroblasts } & \multirow[t]{3}{*}{ Lentiviral (OSKM) } & \multirow[t]{3}{*}{ No } & \multirow[t]{3}{*}{ [25] } \\
\hline & iPSHD22 (47) & & & & \\
\hline & iPSHD34 (42) & & & & \\
\hline
\end{tabular}

\footnotetext{
${ }^{\text {a }}$ These cell lines have been deposited at the National Institute of Neurological Disorders and Stroke (NINDS) repository, https://stemcells.nindsgenetics. org, and were obtained from there by authors of the cited articles

${ }^{\mathrm{b}}$ IVF/PGD - embryos donated after preimplantation diagnostics of in vitro fertilization procedure

${ }^{\mathrm{c}}$ These lines were derived from a homozygous patient
}

cellular stages of nearly homogenous cells, which may reflect the ongoing transitional developmental progress of their in vivo counterparts $[99,100]$. Notably, these distinct expandable states are composed of previously established, selected cell populations, and end-point analyses of these populations may not capture events relevant to step-wise in vivo development. Therefore, for modeling a disease, NSC and NPC should be individually derived from PSC for each experiment, as this method might be more accurate than using the highpassage NSC.

\section{Pluripotency and Self-Renewal}

HTT is not required for the maintenance of a pluripotent state in mouse cells [101]. Additionally, HD mutation does not influence iPSC generation or other features of the pluripotent state, including the expression of pluripotency network genes and the general ability to differentiate into cells that originate from all germ layers [22, 23, 26, 48].

The self-renewal and cell cycle of NPC are altered in the developing and adult HD mice, as well as postmortem HD patient brains [66, 70]. However, no differences have been identified in the proliferation and cell cycle of human HD ESC/iPSC or derived NSC [21, 23, 24]. In contrast, lower proliferation rates have been identified in heterozygous (ESC-derived) and homozygous (brain-derived) NSC from HD 140CAG KI mice vs WT NSC [28]. At another laboratory, heterozygous NSC from the same mice did not exhibit differences in the proliferation or cell cycle, despite similar culture conditions [27]. Similarly, there were no differences between isogenic HD Q20, Q50, and Q111 NSC [27]. These studies used established, high-passage monolayer NSC cultures, which represent a homogenous population of NSC. In contrast, Nguyen et al. used a step-wise neuralization protocol, with NSC analyzed at each step, and they identified an increased proliferation of HD Q111 ESC-derived NSC [29]. Therefore, the discrepant effect of full-length mutant HTT on cell growth characteristics using mouse cell lines may be the result of several variations between cell lines, such as differential culture protocols, exact source of stem cells, and developmental timing of cell isolation.

\section{Differentiation Potential}

HTT is required for NSC rosette formation [65]; however, its loss does not affect the derivation and identity of postrosette, radial glia-like, NS populations [27, 102]. Interestingly, prerosette [26, 30], rosette [24, 42] and NS states [27] may be derived and maintained in HD cells. Reports by Nguyen and colleagues, which are more closely focused on cellular identity transitions, have indicated that both the loss and mutation of HTT in mouse ESC impair the specification and maturation of progenitors within all germ layers [21, 29]. Mutant HTT has been shown to promote neuroectodermal fate (increased numbers of Sox $1+$ and Nestin + cells) and advanced neuronal maturation, as well as increased acquisition of oligodendrocyte fate, at later stages of NSC maturation.

The iPSC derived from transgenic R6/2 mice did not present overt neural differentiation deficits [22]. In contrast, differentiation of ESC from mouse HD 150Q knock-in resulted in more neural precursors (Sox3+) and neurons ( $\beta$-tubulin+), than differentiation of WT NSC [19]. Similar results were 
obtained from adult HD 150Q NSC isolated from SVZ [19]. Furthermore, an increase has been observed in population of Nestin + NPC after 42 days of differentiation of human juvenile HD iPSC $(60,109$, and 180Q) towards striatal-like fates [30]. Interestingly, this retained Nestin+ population, and not mature neuronal cells, appeared to account for the previously shown population of striatal-differentiated juvenile HD cells susceptible to excitotoxic death induced by BDNF withdrawal [26]. BDNF is deficient in HD [103] and it is an important regulator of adult neurogenesis [104]. Therefore, the results indicate that the deficit in BDNF affects immature neuronal progenitors, rather than mature cells, possibly reducing a pool of endogenous cells, which may be able to regenerate the affected brain regions. Two additional groups have reported similar findings, with decreased neural differentiation using a paradigm for efficient differentiation of late-passage, adherent mouse NSC into matured GABAergic neurons [105]. In one report, homozygous, mouse HD Q140 knock-in NSC resulted in fewer Nestin+ NPC, fewer $\beta$ III-tubulin+ neurons, and more Gfap+ glial cells than WT cells [28]. Similarly, fewer neuronal cells (Map2+ and Tau+) were identified in HTT KO cells and heterozygous Q20-140 knock-in cells [27]. However, increases in glial populations (Gfap2+ and S100 $\beta+$ ) were only present in KO cells, which suggests that these putative loss-offunction mechanisms may be rescued by the mouse WT HTT allele in heterozygous HD cells. GABAergic neurons, which are mostly affected in HD, have not been directly assessed in the previously described studies; however, a decreased acquisition of GABAergic cell fate was evident in KO and Q111 mouse ESC [21]. In addition, a decreased neurite length was demonstrated in GABAergic neurons that originated from juvenile human HD iPSC (86Q) [43]. In contrast, the differentiated human ESC displayed an increased number of GABAergic neurons, increased number of neural nodes, but no change in neurite length [34]. Additional studies using human ESC and iPSC with lower adult HD CAG numbers indicated no deficit of maturation into GABAergic projection neurons $[20,23,25,33]$, which suggests greater developmental deficits in GABAergic maturation in the case of juvenileonset HD than in case of adult-onset HD.

Evidence from investigation of differentiation of HD pluripotent models, together with the brain region-specific effects of HTT identified in vivo in mice and patients, indicates that the true effects of mutant HTT may sometimes be masked in artificial cell culture systems. Therefore, researchers should consider using conditions closer to an in vivo situation, e.g., cerebral organoids, to delineate the developmental deficits in HD more precisely, using adult and juvenile human HD cells.

\section{CAG Number and Genomic Stability}

In $\mathrm{HD}$ the $\mathrm{CAG}$ length is dynamic and may undergo changes during gametogenesis and in somatic cells $[106,107]$. The length of the parentally transmitted mutation correlates with the disease onset and severity. However, progression of the disease can be modified by somatic expansions. For instance, vast somatic expansions were identified in premanifest and late-phase, postmortem brains [108]. Large expansions in HD stem cells may change the interpretation of research data, since the length of the mutation might influence the severity of the cellular phenotype. The expansion rate in mice is cell-type dependent and occurs in postmitotic neurons as a consequence of a defective DNA repair of stress-induced DNA breaks [107, 109]. ESC and NSC are characterized by an increased DNA damage response and repair systems, which are essential for their developmental roles [110]. Therefore, the absence of changes $[23,27,35]$ or mild $[26,31]$ changes in the CAG length in human and mouse pluripotent and neural HD stem cells is not surprising. Following differentiation, HD cells do not undergo overt repeat instability for up to 10 weeks. This was assayed in vitro in neuronal [23] and non-neuronal lineages (cardiomyocytes) [90], as well as in vivo in teratomas $[35,90]$. The main exception to the previously described research includes data obtained from R6/1 mouse-derived ESC, in which repeat instability was identified in both pluripotent and neural differentiated states [36]. On average, there was a threefold instability increase when cells were challenged by peroxide-induced oxidative stress. Importantly, peroxide induced the upregulation of specific DNA repair system genes compared with WT cells. These findings suggest that increased susceptibility and reaction to stress-induced DNA are features of HD PSC, compared with non-affected lines.

The overall rate of genomic mutations is lower in PSC than in somatic cells; however, the reprogramming process and prolonged in vitro self-renewal conditions increase the chances of acquiring mutations [111]. Human HD iPSC have an increased rate of genomic instability during reprogramming, when p53 silencing is used in the process [96]. Reprogramming evokes increased replication stress [112] as a result of genome reorganization and extensive proliferation, which may explain the increased rate of CAG expansion identified in the reprogrammed HD iPSC [95]. However, in a long-term cell culture, the genomic integrity of iPSC remained unaffected by the mutant HTT gene [23, 96].

These experiments indicate that CAG instability in HTT gene is limited in PSC and NSC in vitro. Moreover, mutant HTT does not increase genomic mutation rate during continuous culture of PSC in comparison to control cells. Therefore, HD cells should be assessed for mutations as frequently as control PSC. In addition, the substantial expansions characteristic of in vivo conditions may not be identified prior to months of culture of differentiated neurons. The application of stress to cells may enhance $\mathrm{CAG}$ and genomic instability. 


\section{Developmental Hallmarks of Disease in Stem Cell Modeling HD}

\section{HTT Expression and Aggregation}

HTT is an ubiquitously expressed protein [113]; however, its level increases along with brain development [114] or following the in vitro differentiation of PSC into neural lineages $[48,85]$. Moreover, multiple non-canonical HTT isoforms that result from alternative splicing have been described in normal human cells and HD ESC [115]. One alternatively spliced transcript, which excludes HTT posttranslational cleavageregulating exon 10 , has been downregulated during neuronal differentiation, which suggests a role in development. Of the 3 isoforms previously identified in HD patients and mice [116-118], none has been identified in ESC [115].

Mutant HTT forms various oligomeric and polymeric aggregates that differ in terms of protein composition, solubility, cellular localization, and toxicity $[119,120]$. The presence of antibody-detectable inclusions in cells of the CNS and peripheral tissues is a hallmark of disease. However, they are absent in immature PSC and NSC and only begin to emerge in mouse [22] and rhesus [39] transgenic HTT-exon 1 (144Q and 65-72Q, respectively) cells after 1.5-3 weeks of neural differentiation. The formation of inclusions is preceded by the formation of soluble oligomers in rosette-stage NSC, which may be detected via immunoblotting. In human transgenic ESCs with mutant HTT, an exon 1 fragment with juvenile CAG repeat range inclusions and soluble oligomers were identified approximately 2 months after differentiation [37]. However, a longer time span is required for the formation of detectable inclusions in juvenile and adult patient-derived cells because inclusions were detected in neurons after 6 months of culture [25] or transplantation [38], but not up to 2-3 months of differentiation [26,33]. Aggregation may be enhanced with the use of a proteasome inhibitor, e.g., MG132. In one study, the use of MG132 enabled researchers to identify inclusions already in human iPSC with 72Q [38]. Interestingly, mutant HTT RNA also aggregates into toxic foci, which may be identified in human iPSC and derived NPC with only 57 CAG repeats $[97,98]$. Observations in human cells reveal the late onset of aggregation identified in HD patients and lack of aggregates in early developmental stages of cellular HD models.

\section{Differences in Gene Expression}

Gene expression alterations may be the most common and earliest difference detectable in HD cells at the PSC or NSC stage. We have reviewed the research regarding alterations in gene expression and performed a simple meta-analysis to retrieve level 5 GO terms (most detailed GO level) related to developmental biology and signaling pathways related to developmental processes using lists of names of deregulated genes provided by 8 research works. The "Methods" section contains detailed meta-analysis paradigm, and Table 2 contains a list of research works that were included in the analysis.

\section{Methods}

Eight works listed in Table 2, all investigating human cells, were selected for the meta-analysis. The names of the human deregulated genes or proteins represented as names of genes were retrieved from 8 original works and were sorted into 3 separate lists. Names of genes and names of genes corresponding to deregulated proteins were subsequently listed as HUGO Gene Nomenclature Comity symbols (HGNC symbol). We established a list containing names of genes deregulated in NSC and iPSC, a list containing names of genes deregulated in NSC, both ESC and iPSC derived, and a third list containing names of genes deregulated in neurons. We did not distinguish between the deregulated genes/proteins identified in transcriptomic and proteomic experiments, since the aim of the meta-analysis was to identify level 5 GO terms and overrepresented signaling pathways related to developmental biology to generate a global overview reflecting consequences of deregulations of genes and proteins for the cellular phenotype. The cell types, culture conditions, and highthroughput methods used by the authors to identify the deregulations, together with the cutoff values selected in the 8 studies are indicated in Table 2 and Suppl. Table 1. The genes overlapping between lists, and the genes reported in more than one of the 8 studies included in the meta-analysis, were identified using MS Excel formulas (Fig. 3a, b, Suppl. Table 2).

For the retrieval of level 5 GO terms, each list was separately subjected to overrepresentation analysis using the respective tool included in an online version of ConsensusPathDB (CPDB) [121]. "Biological process," "molecular function," and "cellular component" GO terms (level 5, $p$ value cutoff $=0.01$ ) have been selected for the analysis. The retrieved GO terms for each gene list were further manually sorted into 22 arbitrary categories (Suppl. Table 4). The GO annotations related to development were presented in the form of a heatmap (Fig. 3c) [122, 123] using the q values (adjusted $\mathrm{p}$ values) calculated with the use of overrepresentation analysis in CPDB. The green heatmap color denoted the lack of GO term, and the increasing dose of warm colors denoted the presence and increasing statistical significance of GO terms (decreasing q value). For retrieval of biological pathways, each list of genes was again separately subjected to overrepresentation analysis using the respective tool of $\mathrm{CPDB}$, and statistically significant pathways were retrieved using the $p$ value cutoff $=0.01$, and minimum overlap with the input list equaled 10 genes (Suppl. Table 5). 
Table 2 Studies included in the meta-analysis

\begin{tabular}{|c|c|c|c|c|}
\hline Cell type & Markers of cell identity & Method & Cutoff & Reference \\
\hline $\begin{array}{l}\text { iPSC and } \\
\text { iPSC-derived } \\
\text { NSC }\end{array}$ & Nestin (NSC) & RNA-seq & FDR $<0.05$ & {$[42]$} \\
\hline $\begin{array}{l}\text { ESC and } \\
\text { ESC-derived } \\
\text { NSC }\end{array}$ & Nestin, PAX6, Ki67 (NSC) & Gene microarray & $P<0.001$ & {$[76]$} \\
\hline iPSC & Markers for pluripotency & Gene microarray & FDR $<0.05$ & {$[24]$} \\
\hline $\begin{array}{l}\text { iPSC-derived } \\
\text { NSC and } \\
\text { neurons }\end{array}$ & $\begin{array}{l}\text { Nestin, PAX6 (NSC) TUBB3,MAP2A/B, DARPP-32, BCL11B } \\
\text { (neurons differentiated towards striatal-like) }\end{array}$ & Gene microarray & $\begin{array}{l}\text { absolute value of fold } \\
\text { change }>2\end{array}$ & {$[26]$} \\
\hline $\begin{array}{l}\text { iPSC-derived } \\
\text { neurons }\end{array}$ & $\begin{array}{l}\text { TUJ1, MAP2, GABA, GAD65, DARPP-32, Calbindin (neurons } \\
\text { differentiated towards GABAergic striatal like) }\end{array}$ & Gene microarray & $\begin{array}{l}\text { Adjusted } P<0.05 \\
\quad \text { and fold change }>1\end{array}$ & {$[33]$} \\
\hline $\begin{array}{l}\text { iPSC-derived } \\
\text { neurons }\end{array}$ & $\begin{array}{l}\text { TUBB3, DARPP-32, GAT1 (neurons differentiated towards } \\
\text { GABAergic MS-like) }\end{array}$ & Gene microarray & $P<0.05$ & {$[25]$} \\
\hline $\begin{array}{l}\text { ESC and } \\
\text { ESC-derived } \\
\text { neurons }\end{array}$ & $\begin{array}{l}\text { MAP2, GABA, GAD65 (neurons differentiated towards } \\
\text { GABAergic-like) }\end{array}$ & IPG-IEF and LC-MS/MS & $P<0.05$ & {$[34]$} \\
\hline $\begin{array}{l}\text { iPSC and } \\
\text { iPSC-derived } \\
\text { neurons }\end{array}$ & MAP2 (neurons) & $\begin{array}{l}\text { Western blot, 2D } \\
\text { electrophoresis and } \\
\text { LC-MS/MS }\end{array}$ & $P<0.05$ & {$[47]$} \\
\hline
\end{tabular}

\section{GO Terms Identified for Deregulated Genes}

The list of names of differentially expressed genes/proteins, used for meta-analysis, contained 986, 4740, and 454 names of genes for PSC (ESC and iPSC), NSC, and neurons, respectively. Among the listed genes, several deregulated genes overlapped between the analyzed lists; however, only 27 genes were present in all 3 lists (Fig. 3a, b, Suppl. Table 2). Supplementary Tables 2, 3, 4, and 5 present the detailed results of our meta-analysis, including the genes/proteins overlapping between the lists, all GO terms, and genes/proteins reported in more than one study and biological pathways that were represented by more than ten genes. As also described in the "Methods" section, we have established a total number of 22 arbitrary categories. We have selected ten arbitrary categories which represented biological processes related to the developmental aspect of HD and categories with already wellestablished HD phenotypes. Table 3 indicates the selected categories, with the number of related GO terms and the top $5 \mathrm{GO}$ terms in a particular category. The top $5 \mathrm{GO}$ terms were selected by the highest number of genes/proteins from the input list. In addition, the number of GO terms in a particular category was normalized to the total number of GO terms identified for a list of genes of a particular cell type and also presented as the percentage of total number of GO terms (Table 3). The same or similar top 5 GO terms have been shared for 2 or 3 lists of genes in several of the arbitrary categories. The categories sharing GO terms between all gene lists included "differentiation," "neurodevelopment," "cytoskeletal organization, cell-cell interactions," and "apoptosis". The categories sharing GO terms between two gene lists included "proliferation" (NSC and neurons), "development," "control of gene expression," and "metabolism" (PSC and NSC). These findings suggest that similar biological processes, resulting from deregulation of genes/proteins, occur in PSCs and may be sustained during differentiation, until reaching the stage of mature neurons. Noteworthy, similar top 5 GO terms occurred in the analysis, regardless of the protocols for ESC/iPSC derivation, NSC differentiation, neuronal identity, and the inclusion of genes from transcriptomic and proteomic studies. This analysis also confirms that the investigation of HD-associated changes, along the differentiation axis of ESC/iPSC-NSC-neurons, is justified. Finally, the categories most strongly represented by GO terms in PSC and NSC namely, differentiation, neurodevelopment, and development highlight the role of developmental processes, resulting from gene deregulations in HD.

Nevertheless, there are also differences between the analyzed lists of genes. As expected, there were fewer GO terms related to development for neurons than for PSC or NSC. A plausible explanation is the fact that the genes and processes that play a role in the developmental process may have biological functions in mature neurons. There were twice as many GO terms in the neurodevelopment category for NSC than for other lists of genes, which reflects the developmental stages of the analyzed cells. Another evident difference was identified in the metabolism category. The GO terms related to metabolism of nucleic acids dominate among the deregulated genes listed for PSC and NSC, which can likely be attributed to high proliferation rates, whereas in neurons, the category contains mainly GO terms related to metabolism of proteins 
a

b

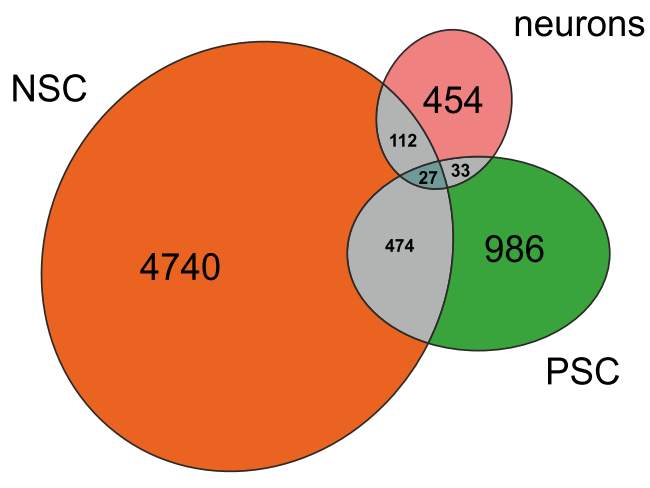

C

\section{GO terms - development}

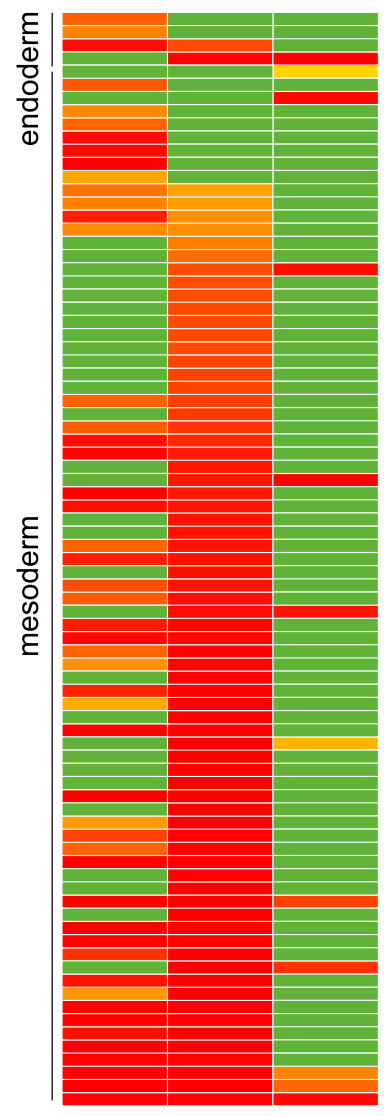

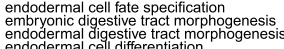

endodermal cell differentiation
tendon develoopment

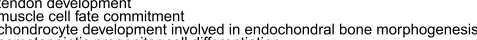

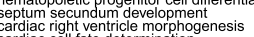

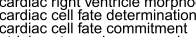

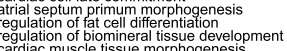

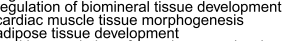

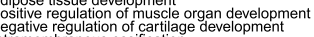

nitramembranous ossificatition
pericyte cell differentiation

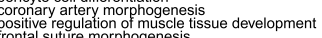

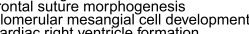

enal vesicle morphogenesis

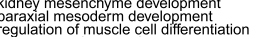

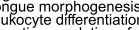

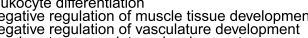

renal system vasculature develooment

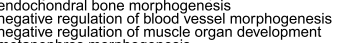

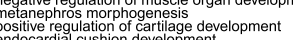

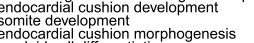

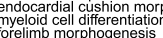

forelimb morrhogenesis
endochondral ossification
cardiac muscle cell development

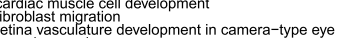

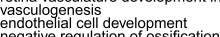

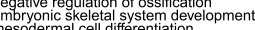

egulation of striated muscle tissue development

embryonic skeletal system morphogenesis

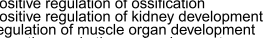

smooth musclet tissue develoopment

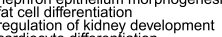

regulation of cartiliage development
cell difierentiatition involved in
indiney development

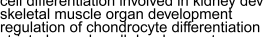

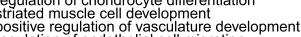

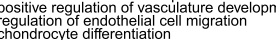

hindlimb morphogenesis

reteric bud development

embryonic limb moronhogeness

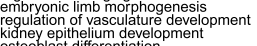

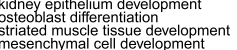

PSC NSC neurons

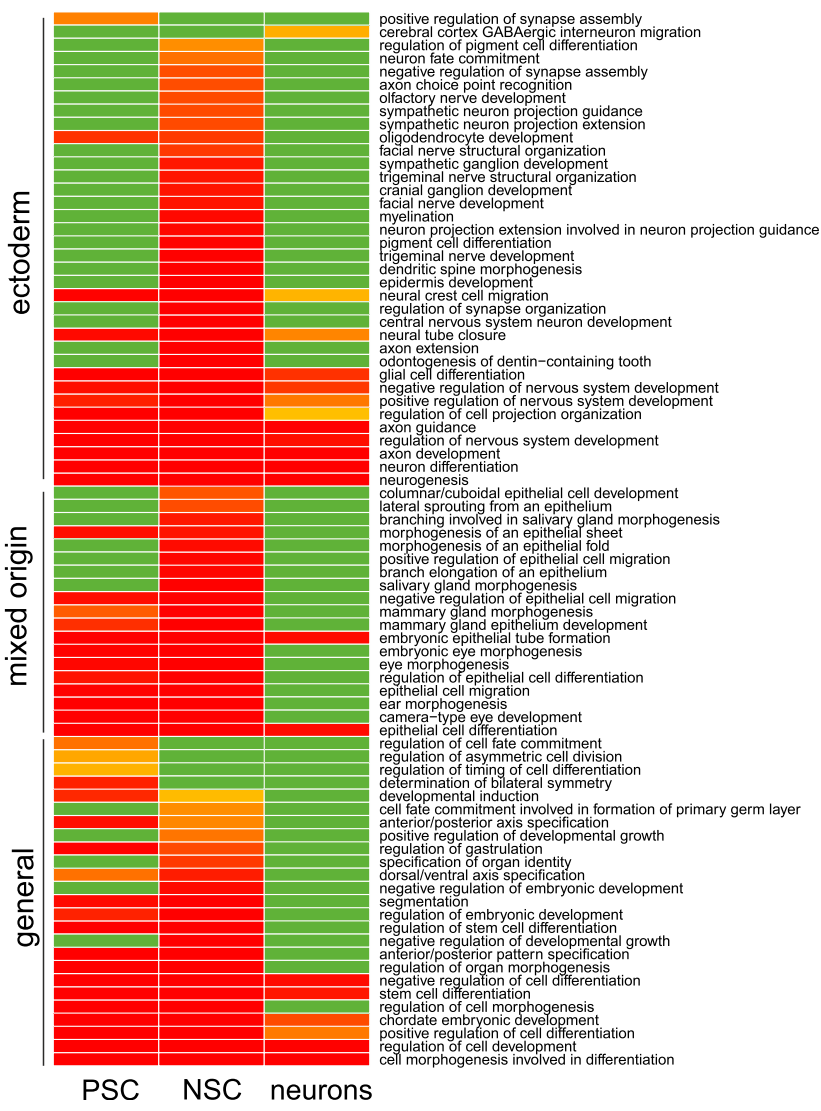

27 genes overlapping between PSC, NSC and neurons

ACACA, ANGPTL4, AXL, CFL1, COL3A1, COL5A1, COL5A2, COMT, CYTL1, DDR2, DLK1, DPYSL5, EFEMP2, GPX1, PSMD5, S100A11, S100A4, SDC2, TENC1, THBS1, VIM

\begin{tabular}{|c|c|c|}
\hline \multicolumn{3}{|c|}{$\begin{array}{l}\text { Top } 5 \mathrm{GO} \text { terms for the list of } 27 \text { genes } \\
\text { overlapping between PSC, NSC and neurons }\end{array}$} \\
\hline GO term & q-value & Genes \\
\hline $\begin{array}{l}\text { positive regulation of } \\
\text { signal transduction }\end{array}$ & 0.016482 & $\begin{array}{l}\text { NPNT, GSTO1, PSMD5, } \\
\text { THBS1, GPX1, S100A4, } \\
\text { COL3A1, AXL }\end{array}$ \\
\hline $\begin{array}{l}\text { positive regulation of } \\
\text { cell communication }\end{array}$ & 0.016482 & $\begin{array}{l}\text { NPNT, GSTO1, PSMD5, } \\
\text { THBS1, GPX1, S100A4, } \\
\text { COL3A1, AXL }\end{array}$ \\
\hline $\begin{array}{l}\text { regulation of } \\
\text { intracellular signal } \\
\text { transduction }\end{array}$ & 0.018076 & $\begin{array}{l}\text { NPNT, GSTO1, PRDX1, } \\
\text { THBS1, GPX1, S100A4, } \\
\text { COL3A1, AXL }\end{array}$ \\
\hline calcium ion binding & 0.000213 & $\begin{array}{l}\text { EFEMP2, THBS1, NPNT, } \\
\text { DLK1, S100A11, S100A4, } \\
\text { MAN1A1 }\end{array}$ \\
\hline $\begin{array}{l}\text { negative regulation of } \\
\text { cell death }\end{array}$ & 0.040684 & $\begin{array}{l}\text { GPX1, ANGPTL4, CFL1, } \\
\text { AXL,THBS1 }\end{array}$ \\
\hline
\end{tabular}


4 Fig. 3 Meta-analysis reveals common genes/proteins and developmental GO terms for PSC, NSC, and neurons.a Names of genes that overlap between the lists of deregulated genes for PSC, NSC, and neurons. Venn diagram indicates number of genes/proteins included in the metaanalysis that overlap between only two or all three of the analyzed lists of genes. Detailed list of overlapping genes is available in Supplementary Fig. 2 (Venn diagram generated with eulerAPE v3). b Top: list of 27 genes/proteins that overlap between all three lists of genes for PSC, NSC, and neurons. Bottom: top 5 GO terms (level 5) containing the highest number of genes/proteins from the input list with 27 genes. The $q$ values and list of members are provided. $\mathbf{c}$ Heatmap demonstrates GO terms (level 5) related to development, which were detected by the metaanalysis in the lists of genes for PSC, NSC, and neurons. Absence of developmental GO term (green), the increasing dose of warm colors (orange to red) denotes the increasing statistical significance of GO term (decreasing $q$ value for a particular term). GO terms in the heatmap are ordered according to germ layers and general events (Heatmap generated with R software v3.3.0) (Color figure online)

and neurotransmitters. Furthermore, there is no GO term related to lipid metabolism in neurons, whereas it is present in the top $5 \mathrm{GO}$ terms in the "cell response" category for PSC and NSC (Suppl. Table 4), which may be associated with a higher demand for cholesterol in the early stages of embryonic development [22]. Interestingly, NSC and neurons are enriched in GO terms related to cell stress compared to fewer GO terms in PSC. This finding corresponds with the demonstration revealing that after differentiation, HD cells are more vulnerable to stress and death evoked by withdrawal of BDNF and other growth factors [24]. There have been several, additional interesting categories and GO terms representing biological processes, implying their role in HD. For instance, in the meta-analysis, there have been such GO terms as "response to wounding" or "axon regeneration" (Suppl. Tables 3 and 4), which emphasizes the occurrence of processes related to neural degeneration in $\mathrm{HD}$ or GO terms related to immune response underlining its important role in HD [124]. In our analysis, we did not detect GO terms directly related to epigenetics. However, these changes were detected in mouse and human ESC, NPC, and neurons that linked mutant HTT and chromatin status during development [32, 34].

\section{Signaling Pathways}

Several signaling pathways involved in embryonic development are also affected in HD [125]. For example, the MEK/ ERK signaling pathway, which is a part of the MAPK signaling pathway, plays a neuroprotective role in HD. In addition, the TGF-beta signaling pathway is upregulated in HD human cells and a rat model [125]. The meta-analysis performed for the purposes of this review also identified overrepresented, developmental signaling pathways among the deregulated genes and proteins identified in iPSC and NSC, collected from the eight research works and listed in Table 2. In iPSC, the developmental signaling pathways [126], represented by at least ten deregulated members (proteins/genes) as a cutoff (cutoff $=10, p<0.01$ ), included the TGF-beta, Wnt, PI3KAkt, Hippo, MAPK, EGFR1, and Rap1 signaling pathways semaphorin interactions, and other signaling pathways. In NSC, the pathways included TGF-beta, beta catenin, PI3KAkt, EGFR1, PDGFR-beta, Rap1, Hippo, BDNF, semaphorin interactions, and other pathways (cutoff $=10, p<0.01$ ). In terminally differentiated neurons, the signaling pathways with at least ten deregulated proteins included the MAPK family, PI3K-Akt, EGFR1, PDGF, NGF, and other $($ cutoff $=10$, $\mathrm{p}<0.01$ ) (Suppl. Table 5). In addition to high-throughput screens, the HD signaling pathways have also been investigated in a more detailed way, and early HD phenotypes have been identified in stem cells. For instance, the deregulation of the MAPK, Wnt, and p53 pathways was identified in mouse and human iPSC [48]. A study by Ring et al. indicates that NSC derived from HD human iPSC (72Q) were rescued from apoptosis when TGF-beta was added to growth factordeprived culture medium (without bFGF and LIF) [42]. However, the apoptotic phenotype was masked in a complete culture medium, potentially because the TGF-beta signaling, which is putatively protective, was upregulated in the HD NSC. Therefore, it must be noted that the signaling pathway inhibitors and activators used during stem cell culture and differentiation may modify or mask the HD phenotypes related to their activity in vivo.

The p53 tumor suppressor protein is a regulator of cell fate specification, as the p53-null mutation in mice leads to multiple developmental defects, including brain exencephaly [127, 128]. Embryonic lethality may be induced by disrupting p53 transactivation functions via the $\mathrm{KO}$ of the $\mathrm{p} 53$ regulators, the E3 ubiquitin-protein ligases: MDM2 or MDM4 [129], or the transcription activation domains, vital for interactions [130]. In $\mathrm{HD}, \mathrm{p} 53$ influences the disease phenotype via multiple pathways, which have previously been reviewed in a comprehensive way [125]. In addition, the absence of $\mathrm{p} 53$ in $\mathrm{Hdh}^{140 \mathrm{Q} / 140 \mathrm{Q}}$ mouse, which presents a number of repeats in the juvenile range, results in increased formation of aggregates in the brain [131]. Research on adult HD cells or HD patient brains indicates that the $\mathrm{p} 53$ expression or activity was upregulated at later stages of disease and mediated apoptosis [125].

In human undifferentiated and neuronally differentiated HD iPSC (86Q), p53 was extensively translocated into mitochondria, which was accompanied by $\mathrm{p} 53$-dependent activation of pathways that led to neuronal maturation defects and apoptosis [43]. Both defects were repaired by p 53 silencing or mitochondria fission inhibition [43]. Moreover, Chae et al. identified increased levels of $\mathrm{p} 53$ phosphorylation in human HD iPSC (71 CAG) [47]. In contrast, we have shown that p53 is downregulated in undifferentiated mouse iPSC from the YAC128 model (128 CAG) and also in human iPSC sampled from a juvenile HD patient (onset at 3 years; 109 CAG) [43]. The $\mathrm{p} 53$ remained unchanged in iPSCs independently derived from the same patient as in the work of Chae et al. containing 
Table 3 Meta-analysis summary: number of GO terms and names of top $5 \mathrm{GO}$ terms grouped into 10 arbitrary categories describing relevant biological and developmental processes and HD phenotypes. Each arbitrary category contains the indicated number of GO terms, which is also expressed as a percentage of total number of GO terms for particular cell type. Numbers in brackets indicate number of genes from the input list, which were assigned by CPDB for each GO term

\begin{tabular}{|c|c|c|c|}
\hline Category & PSC -292 total GO terms, 986 genes & NSC -445 GO terms, 4740 genes & Neurons-191 GO terms, 454 genes \\
\hline \multirow{2}{*}{$\begin{array}{l}\text { Proliferation, cell } \\
\text { cycle, and growth } \\
\text { Top } 5 \text { terms }\end{array}$} & $13 \mathrm{GO}$ terms; $4.45 \%$ & $21 \mathrm{GO}$ terms; $4.80 \%$ & $10 \mathrm{GO}$ terms; $5.23 \%$ \\
\hline & $\begin{array}{l}\text { Positive regulation of cell proliferation } \\
\text { (62), negative regulation of cell } \\
\text { proliferation (50), regulation of } \\
\text { mitotic cell cycle (32), regulation of } \\
\text { epithelial cell proliferation (31), } \\
\text { positive regulation of cell cycle (21) }\end{array}$ & $\begin{array}{l}\text { Positive regulation of cell proliferation } \\
\text { (276), negative regulation of cell } \\
\text { proliferation (224), regulation of cell } \\
\text { cycle process (146), negative } \\
\text { regulation of cell cycle (139), mitotic } \\
\text { cell cycle phase transition (130) }\end{array}$ & $\begin{array}{l}\text { Positive regulation of cell proliferation } \\
\text { (34), negative regulation of cell } \\
\text { proliferation (27), regulation of cell } \\
\text { cycle process (20), negative regulation } \\
\text { of cell cycle (19), positive regulation } \\
\text { of cell cycle (16) }\end{array}$ \\
\hline Differentiation & 24 GO terms; $8.22 \%$ & 24 GO terms; $5.39 \%$ & 9 GO terms; $4.71 \%$ \\
\hline Top 5 terms & $\begin{array}{l}\text { Cell morphogenesis involved in } \\
\text { differentiation (89), positive } \\
\text { regulation of cell differentiation (67), } \\
\text { negative regulation of cell } \\
\text { differentiation (53), epithelial cell } \\
\text { differentiation (45), stem cell } \\
\text { differentiation (42) }\end{array}$ & $\begin{array}{l}\text { Cell morphogenesis involved in } \\
\text { differentiation (378), positive } \\
\text { regulation of cell differentiation (297), } \\
\text { negative regulation of cell } \\
\text { differentiation (221), epithelial cell } \\
\text { differentiation (204), stem cell } \\
\text { differentiation (151) }\end{array}$ & $\begin{array}{l}\text { Cell morphogenesis involved in } \\
\text { differentiation (58), negative } \\
\text { regulation of cell differentiation (30), } \\
\text { positive regulation of cell } \\
\text { differentiation (29), epithelial cell } \\
\text { differentiation (27), stem cell } \\
\text { differentiation (19) }\end{array}$ \\
\hline Development & 59 GO terms; $20.21 \%$ & 93 GO terms; $20.90 \%$ & $12 \mathrm{GO}$ terms; $6.28 \%$ \\
\hline Top 5 terms & $\begin{array}{l}\text { Regulation of cell development (61), } \\
\text { chordate embryonic development } \\
\text { (58), regulation of cell morphogenesis } \\
\text { (43), striated muscle tissue } \\
\text { development (38), regulation of } \\
\text { vasculature development (30) }\end{array}$ & $\begin{array}{l}\text { Regulation of cell development (303), } \\
\text { chordate embryonic development } \\
\text { (243), regulation of cell } \\
\text { morphogenesis (193), striated muscle } \\
\text { tissue development (138), } \\
\text { camera-type eye development (117) }\end{array}$ & $\begin{array}{l}\text { Regulation of cell development (35), } \\
\text { chordate embryonic development } \\
(25), \text { striated muscle tissue } \\
\text { development (16), endochondral bone } \\
\text { morphogenesis (12), mesenchymal } \\
\text { cell development (12) }\end{array}$ \\
\hline Neurodevelopment & 13 GO terms; $4.45 \%$ & 30 GO terms; $6.74 \%$ & 12 GO terms; $6.28 \%$ \\
\hline Top 5 terms & $\begin{array}{l}\text { Neurogenesis (121), neuron } \\
\text { differentiation (109), axon } \\
\text { development (58), Regulation of } \\
\text { nervous system development (54), } \\
\text { axon guidance (44) }\end{array}$ & $\begin{array}{l}\text { Neurogenesis (578), neuron } \\
\text { differentiation (504), regulation of } \\
\text { nervous system development (282), } \\
\text { axon development (264), axon } \\
\text { guidance (184) }\end{array}$ & $\begin{array}{l}\text { Neurogenesis (74), neuron } \\
\text { differentiation (60), axon } \\
\text { development (36), regulation of } \\
\text { nervous system development (30), } \\
\text { axon guidance (27) }\end{array}$ \\
\hline $\begin{array}{l}\text { Control of gene } \\
\text { expression }\end{array}$ & $18 \mathrm{GO}$ terms; $6.16 \%$ & $16 \mathrm{GO}$ terms; $3.60 \%$ & $4 \mathrm{GO}$ terms; $2.09 \%$ \\
\hline
\end{tabular}

expression

Top 5 terms

Regulation of gene expression (206), transcription, DNA-templated (179), sequence-specific DNA binding (63), regulatory region DNA binding (52), transcriptional activator activity, RNA polymerase II core promoter proximal region sequence-specific binding (21)

Signaling pathways

18 GO terms; $6.16 \%$

Top 5 terms

Cytoskeletal organization, cell-cell interactions Top 5 terms transduction (71)
Cell surface receptor signaling pathway (166), intracellular signal transduction (151), positive regulation of signal transduction (94), regulation of intracellular signal transduction (90), negative regulation of signal

13 GO terms; $4.45 \%$

Positive regulation of cell communication (106), negative regulation of cell communication (75), actin cytoskeleton (33), positive
Regulation of gene expression (1057), transcription, DNA-templated (901), sequence-specific DNA binding (281), regulatory region DNA binding (240), transcriptional activator activity, RNA polymerase II core promoter proximal region sequence-specific binding (91)

29 GO terms; $6.52 \%$

Cell surface receptor signaling pathway (839), intracellular signal transduction (805), regulation of intracellular signal transduction (454), positive regulation of signal transduction (430), negative regulation of signal transduction (325)

22 GO terms; $4.94 \%$

Structure-specific DNA binding (16), DNA conformation change (12), protein-DNA complex assembly (10), establishment of protein localization to chromosome (2)

8 GO terms; $4.19 \%$

Cell surface receptor signaling pathway (90), intracellular signal transduction (82), regulation of intracellular signal transduction (50), positive regulation of signal transduction (42), negative regulation of signal transduction (37)

14 GO terms; $7.33 \%$

Positive regulation of cell communication (506), microtubule cytoskeleton (274), negative regulation of cell communication
Positive regulation of cell communication (52), negative regulation of cell communication (38), actin cytoskeleton (29), positive 
Table 3 (continued)

\begin{tabular}{|c|c|c|c|}
\hline Category & PSC -292 total GO terms, 986 genes & NSC -445 GO terms, 4740 genes & Neurons-191 GO terms, 454 genes \\
\hline & $\begin{array}{l}\text { regulation of cell adhesion (25), } \\
\text { regulation of cell-cell adhesion (24) }\end{array}$ & $\begin{array}{l}\text { (355), actin cytoskeleton (182), actin } \\
\text { filament organization (117) }\end{array}$ & $\begin{array}{l}\text { regulation of cell adhesion (20), actin } \\
\text { filament organization (18) }\end{array}$ \\
\hline $\begin{array}{l}\text { Oxidative and other } \\
\text { cell stress }\end{array}$ & 3 GO terms; $1.03 \%$ & $11 \mathrm{GO}$ terms; $2.47 \%$ & $10 \mathrm{GO}$ terms; $5.24 \%$ \\
\hline Top 5 terms & $\begin{array}{l}\text { Cellular response to reactive oxygen } \\
\text { species (12), stress fiber (8), response } \\
\text { to X-ray (5) }\end{array}$ & $\begin{array}{l}\text { Stress-activated MAPK cascade (82), } \\
\text { response to UV (43), cellular response } \\
\text { to reactive oxygen species (40), } \\
\text { cellular response to alcohol (37), stress } \\
\text { fiber assembly (32) }\end{array}$ & $\begin{array}{l}\text { Cellular response to reactive oxygen } \\
\text { species (11), stress fiber (7), regulation } \\
\text { of oxidative stress-induced cell death } \\
\text { (6), cellular response to ionizing radi- } \\
\text { ation (6), regulation of response to } \\
\text { oxidative stress (6) }\end{array}$ \\
\hline Apoptosis & $6 \mathrm{GO}$ terms; $2.05 \%$ & $8 \mathrm{GO}$ terms; $1.80 \%$ & $10 \mathrm{GO}$ terms; $5.24 \%$ \\
\hline Top 5 terms & $\begin{array}{l}\text { Apoptotic process (112), regulation of } \\
\text { programmed cell death (97), negative } \\
\text { regulation of cell death (67), positive } \\
\text { regulation of cell death (40), neuron } \\
\text { apoptotic process (24) }\end{array}$ & $\begin{array}{l}\text { Apoptotic process (570), regulation of } \\
\text { programmed cell death (447), } \\
\text { negative regulation of cell death (289), } \\
\text { apoptotic signaling pathway (198), } \\
\text { positive regulation of cell death (197) }\end{array}$ & $\begin{array}{l}\text { Apoptotic process ( } 73) \text {, regulation of } \\
\text { programmed cell death (66), negative } \\
\text { regulation of cell death(48), apoptotic } \\
\text { signaling pathway (27), positive } \\
\text { regulation of cell death (26) }\end{array}$ \\
\hline Metabolism & 42 GO terms; $14.38 \%$ & 61 GO terms; $13.71 \%$ & 33 GO terms; $17.28 \%$ \\
\hline Top 5 terms & $\begin{array}{l}\text { Regulation of cellular biosynthetic } \\
\text { process (203), regulation of } \\
\text { nucleobase-containing compound } \\
\text { metabolic process (198), regulation of } \\
\text { macromolecule biosynthetic process } \\
\text { (187), positive regulation of cellular } \\
\text { metabolic process (183), RNA bio- } \\
\text { synthetic process (182) }\end{array}$ & $\begin{array}{l}\text { Regulation of cellular biosynthetic } \\
\text { process (1055), regulation of } \\
\text { nucleobase-containing compound } \\
\text { metabolic process (999), regulation of } \\
\text { macromolecule biosynthetic process } \\
\text { (996), RNA biosynthetic process } \\
\text { (926), regulation of RNA metabolic } \\
\text { process (907) }\end{array}$ & $\begin{array}{l}\text { Positive regulation of cellular metabolic } \\
\text { process }(87), \text { positive regulation of } \\
\text { macromolecule metabolic process } \\
\text { (76), regulation of protein metabolic } \\
\text { process }(75), \text { regulation of cellular } \\
\text { protein metabolic process }(68), \\
\text { negative regulation of cellular } \\
\text { metabolic process }(65)\end{array}$ \\
\hline
\end{tabular}

$71 \mathrm{CAG}$ repeats (disease onset at 14 years) [48]. Moreover, p53 has been identified as a top 5 gene regulator of the pathways altered after HTT mutation correction in hiPSC-derived NSC [42]. It is plausible that the p53 deregulation profile in juvenile HD stem cells is dependent on the number of CAG repeats. It is also possible that the expression level and activity of p53 may be different in juvenile HD and in adult HD. However, to verify these hypotheses, data from more HD iPSC lines, preferably isogenic and ranged from low to high CAG repeat numbers, are needed. The mitochondrial and apoptotic effects that may result from altered p 53 activity will be discussed in subsequent sections.

\section{Mitochondrial Dysfunction}

One of the most extensively investigated features of HD pathology includes complex mitochondrial impairments involving multiple aspects of organelle biology [132-134]. However, their genesis and impact on disease pathogenesis are insufficiently understood. The downstream consequences of these changes may include susceptibility to excitotoxicity, reactive oxygen species (ROS)-induced DNA damage, and apoptosis.

The mitochondrial content, life cycle, activity, and dynamics are important regulators of embryonic and brain development, and their dysfunction may lead to neurodevelopmental disorders [135]. Remarkably, Ismailoglou et al. reported that mouse ESC with HTT KO had increased glucose uptake from the medium. The cells were incapable of sufficient mitochondrial ATP synthesis and therefore turned to glycolytic respiration and lowered their oxygen consumption [41]. The mitochondria in these cells were aberrantly structured; however, no polarization defects were identified. Similarly, the ESC containing mutant HTT(140Q) from knock-in HD model exhibited increased glucose consumption; however, in contrast to $\mathrm{KO}$ cells, the oxidative phosphorylation respiration increased, with no evidence of alterations in the mitochondrial structure. On the other hand, Jacobsen et al. reported no ATP/ADP ratio changes in KO mouse ESC and a decreased ATP/ADP ratio in Q111 knock-in cells [40]. The discrepancy between these two studies likely resulted from the different culture conditions and different reference cells. Ismailoglou et al. cultured cells in feeder-free and defined serum-free ground-state $(2 \mathrm{i}+\mathrm{LIF})$ conditions [136], whereas Jacobsen et al. maintained the cells in undefined serum replacement conditions on feeders, with LIF only. Nevertheless, these studies, combined with proteomic research on human ESC and iPSC [34, 47], have identified a substantial number of alterations in the metabolome and expression of genes related to mitochondrial function, energy 
metabolism, and metabolite synthesis. The metabolic impairments induced by the mutation or loss of the HTT gene include dysregulation of the lipid and cholesterol synthesis pathways, which have previously been shown to be affected in patients [137], PSC [22, 34, 41], and differentiated neurons [26].

Research regarding human iPSC-derived NSC has indicated that calcium signaling and the ATP/ADP ratio are decreased in these cells [26], and genetic correction of mutant HTT alleles enhanced the maximum respiration rate towards control cell levels [24]. Guo et al. focused on mitochondrial fission deficits in multiple cellular and mouse models of HD [43]. In their models, excessive accumulation of the fission-driving protein Drp1 causes the translocation of p53 to mitochondria, which leads to accumulation of ROS, mitochondrial fragmentation, and, consequently, apoptosis. In HD iPSC, they identified increased levels of Drp1 and p53 in mitochondria, whereas iPSC-derived GABAergic neurons, including MSNs, had defective, fragmented mitochondria neurites with a decreased membrane potential, decreased ATP/ADP ratios, increased ROS, and enhanced apoptosis. Both the selective Drp1 inhibitor P110-TAT and p53 silencing rescued these phenotypes and normalized the neurite lengths. The treatment also turned out to be beneficial in R6/2 mice, which validated research in iPSC HD cellular models.

The altered ROS accumulation and oxidative stress response represent other mitochondria-related impairments featured in HD [138]. As described, an increased ROS content has been identified in human MSNs [43]. If not neutralized, excess ROS may induce DNA damage and alter ROS signaling pathways, which may regulate proliferation and differentiation processes [139]. The phenotype was also shown in mouse knock-in ESC- and brain-derived NSC with $140 \mathrm{Q}$ [28]. Interestingly, the loss of HTT in KO-NSC did not cause ROS accumulation. In human iPSC, the expression levels of multiple antioxidant proteins were altered, including the downregulation of SOD1 and GST and the upregulation of proteins in the PRX family [47]. These changes were sustained throughout differentiation into mature neurons. We have also shown [48], in both adult and juvenile human iPSC and mouse YAC128 iPSC, that SOD1 is altered; however, in our case, it was upregulated. This discrepancy again points to the potential effects of the culture conditions, as we used feeder-free defined Essential 8 conditions for culture of human iPSC. Nevertheless, these changes may indicate that an altered redox homeostasis and increased susceptibility to oxidative stress, including the ultimate solution, apoptosis (which will be described later), are present in iPSC.

Another crucial mitochondria-related pathomechanism of HD is excitotoxicity, in which $N$-methyl-D-aspartate receptors (NMDARs) are overactivated in response to glutamate. NMDAR overstimulation leads to dysregulation of the cellular $\mathrm{Ca}^{2+}$ homeostasis, which is typically maintained by mitochondria and endoplasmic reticulum, and ultimately leads to cell death $[140,141]$. The propensity for neuronal excitotoxicity in mature brains has been evaluated using ESC/iPSC-derived neurons. The calcium homeostasis was disrupted in MSN-like cells derived from human HD iPSC [25]. The abnormal increase in the cellular calcium entry, which was regulated by calcium storeoperated channels, was effectively blocked by EVP4593, thereby leading to decreased cell death rates. Exposure to both physiological and pathological glutamate concentrations exacerbated the $\mathrm{Ca}^{2+}$ imbalance and led to increased apoptosis in striatal-like HD cell lines, from adult and juvenile patient iPSC [26]. It has subsequently been demonstrated that the cells that died in this in vitro culture were not mature neurons; instead, they were Nestin+ striatal-like NPC, and the excitotoxicity may be mediated by the loss of neuroprotective BDNF via the TrkB pathway [30]. BDNF is a key player in HD pathogenesis [141], and its downregulation has been identified following differentiation to NSC [24, 44].

It is still to be determined how mitochondrial deficits correspond to defects in the differentiation and maturation of HD cells. Moreover, the early presence of a mitochondrial phenotype in pluripotent models may provide additional insights into the mitochondrial impairments in HD, which are of particular interest as a result of several contradictory observations concerning metabolism and mitochondria in HD [132].

\section{Autophagy and UPS}

Autophagy is a part of the stress response system responsible for the degradation of dysfunctional or toxic protein aggregates and organelles, including mitochondria, and pathogens. In this process, proteins and organelles to be cleared are delivered to lysosomes, the effectors of degradation. Autophagy is important for stem cell self-renewal and development, and it is essential for the maintenance of stress-sensitive, postmitotic neurons [142, 143]. In HD, mutant HTT impairs the autophagosome trafficking and thus the fusion of autophagosomes with lysosomes [144]. The mRNA expression of $T f e b$, a master regulator of autophagy and lysosomes, along with their targets, Tppl and Ctsf, has been shown to be increased in iPSC and neurons derived from R6/2 mice [22]. These increases resulted in a greater number of lysosomes in iPSC. An increased number of lysosomes have also been identified in an adult patient's iPSC and the derived neurons [23]. Additional studies have confirmed an increased number of autophagosomes, lysosomes, and mitophagy (mitochondrial autophagy) in iPSC-derived MSN-like neurons [25]. In these cells, lysosome content was decreased following treatment with the $\mathrm{Ca}^{2+}$ influx-repairing agent EVP4593. Interestingly, 
astrocytes derived from the juvenile HD patient iPSC had an increased content of cytoplasmic vacuoles, some of which were autophagosomes [94].

Another mechanism for clearance of unwanted proteins is the unfolded protein response (UPR)/ubiquitin-proteasome system (UPS) pathway. In HD, the accumulation and aggregation of mutant HTT result from a failure of the UPS to efficiently deal with polyQ-expanded HTT [144, 145], which may be influenced by deficits in the preceding UPR pathway [146]. Consistent with this evidence, human ESC and derived neurons demonstrate altered levels of the ubiquitination pathway proteins [34], whereas correction of the HD mutation in human iPSC results in the upregulation of UPR-related gene expression $[24,146]$.

\section{Apoptosis}

Programmed cell death may be mediated by apoptosis, which is activated by a caspase cascade. Caspase activity is elevated in cellular and animal models of HD and postmortem brain tissues obtained from HD patients [147]. In vivo experiments have also shown that modulation of the HTT level results in apoptotic responses in the developing brain. For instance, the depletion of HTT in neuroepithelial cells by the shRNA construct may lead to disturbed cell migration from ventricular zone to caudoputamen and reduced proliferation or increased apoptosis in the cortex of developing 12.5-day-old embryo. Both the neuronal survival and proliferation may be partially rescued by over $40 \%$ caspase- 9 knockdown [148]. Notably, mutant Hdh CAG knock-in NSC exhibit overactivity of caspase-3/7 [147, 149]. Similarly, the activity of caspase-3/7 plays a key role in apoptosis in HD, and it is increased in a CAG repeat length-dependent manner in mouse ESC-derived NSC during differentiation [27]. Even the cells without endogenous HTT exhibit high levels of caspase activity [150, 151]. However, mutation of the HTT gene in human ESC or iPSC did not induce programmed cell death, as indicated by the activated caspase-3 staining [23]. Furthermore, there was no difference in the caspase-3/7 activity between genetically corrected (21 CAG repeats) and uncorrected human isogenic HD iPSC (72 CAG repeats) [24]. Both corrected and uncorrected HD iPSC were differentiated into NSC, followed by stress induction through withdrawal of growth-supporting factor from the culture medium. The uncorrected HD NSC responded to such a withdrawal with increased apoptosis as assessed by increased TUNEL staining and increased caspase$3 / 7$ activity, while the corrected NSC were "cured" of these effects. The results suggest that polyglutamine expansion makes iPSC and NSC more sensitive to cell death on their differentiation route towards neurons; however, they become sensitive to polyQ-induced apoptosis at a relatively early stage of neuronal development.
Apoptosis was also increased following stress conditions in cells obtained from HD patients or animal models [147, $152,153]$. In the pluripotent HD models, after 3 weeks of differentiation of juvenile human NSC, there has been a gradual decrease in the number of active neurons, with eventual cell death by the end of the third week [26]. The HD cultures developed a severe phenotype and exhibited high levels of mutant HTT expression. Furthermore, after differentiation using a modified, more protective protocol, neurons exhibited increased caspase-3/7 activity and mortality following BDNF withdrawal. This effect was reversed by the addition of BDNF, at 4 times of its normal concentration, to the media of the HD cell cultures [26]. The selective inhibition of ATM-mediated signaling may also confer the protection of HD iPSC-derived striatal neurons from BDNF withdrawal [45]. Multiple reports have identified stressors that induce increased levels of apoptosis in PSC-derived $\mathrm{HD}$ neurons, e.g., $\mathrm{H}_{2} \mathrm{O}_{2}$ (oxidative stress) $[33,39]$, 3methyladenine (autophagy inhibitor), MG-132 (proteasome inhibitor) [105] and staurosporine (broad-spectrum kinase inhibitor) [34]. In HD, neuronal dysfunction and death are more widespread, notably in the cases of longer CAG repeats, which suggests that the toxicity mediated by stress factors may not be exclusively limited to striatal neurons. It should be noted that severe MSN death characteristic for HD is not as relevant in mouse models. For example, in knock-in mice, the phenotype can hardly be observed until late life unless mice are homozygous and have CAG repeat numbers over $>140$. Therefore, human and primate HD PSC are more suitable for research on apoptosis.

\section{Cell Adhesion}

Cell adhesion and cytoskeletal molecules, including Ncadherin and actins, are indispensable for normal brain development because of their vital roles in cell orientation, migration, communication (including apoptotic signaling), and the formation of brain structures [154, 155]. As previously discussed, in the absence of HTT, the rosetteless phenotype may occur in NSC as a result of increased activity of ADAM10 metalloproteinase, which mediates increased cleavage of N-cadherin [65]. Moreover, $\mathrm{N}$-cadherin deficits have been identified in the brains of HD Q111 knock-in mice [156].

The N-cadherin pathway is directly affected by mutant HTT, and genetic correction of the mutant allele has resulted in upregulated expression of several protocadherins in human iPSC and iPSC-derived NSC [24, 42]. Moreover, human iPSC-derived NSC lines with $60 \mathrm{Q}$ and $180 \mathrm{Q}$ bound less phalloidin peptide, which suggests changes in the actin cytoskeleton, and displayed a decrease in the adhesive capabilities via cell cluster formation assays [26]. The existence of actin deficits in HD NSC is further supported by the motility 
reduction identified in mouse ESC-derived NSC, with a $110 \mathrm{Q}$ knock-in mutation or the loss of HTT [28], as well as the expression changes in the motility and cytoskeleton pathways, identified following neuronal differentiation of $140 \mathrm{Q}$ knockin mouse ESC, human ESC, and iPSC [19, 26, 34, 47]. Taken together, these findings suggest that cytoskeletal and adhesion molecules may influence the functional differentiation and survival deficits that occur in stem cell models of HD and during in vivo development of HD models.

\section{Conclusion}

In conclusion, this review summarizes current evidence for the existence of a developmental, pathogenic phase in the progression of HD, which suggests that the traditional view that HD is solely an adult, neurodegenerative disease should be revisited. The most convincing evidence includes the effects of induced expression and the selective deficiency of normal or mutant HTT in developmental stages. Potential mechanisms are presented, based on data from in vivo models. Pluripotent, neuronal stem cells and mature neurons derived from these cells also exhibit an array of phenotypes characteristic of HD patients and models. Finally, the GO terms retrieved for the deregulated genes in HD cell models and deregulated signaling pathways (most importantly, TGF- $\beta$, Wnt, and MAPK signaling) are directly related to development and neurogenesis, affected in vitro and in vivo. Taken together, ESC/iPSC appear to be the best cellular models, which are available at present to investigate the impact of neurodevelopmental defects in HD. The data also indicate the need for optimization of human iPSC models, including reprogramming and differentiation protocols, the use of isogenic human stem cells, cerebral organoids, and defined media, for the purposes of consistent observation of HD phenotypes. The selective differentiation of ESC/iPSC into neuronal cell types provides an additional opportunity to model late $\mathrm{HD}$ phenotypes because the neurons may be maintained for extended periods of time in culture. In this model, later phenotypes may be enhanced by the application of stressors or aging factors that induce age-related events, such as progerin [157, 158]. The developmental characteristics of HD have crucial implications for therapy. It remains unclear which therapeutic strategy is most appropriate and when the treatment should be initiated. For cell therapy, a transplant may directly provide protective and trophic agents, or it may be designed to mature in vivo, developing functional neurons within the network of host cells.

Neurodegenerative disorders are traditionally recognized as diseases of late onset; however, this perception may be shifting. A suitable example demonstrating the need for this perception change can be the evidence showing that healthy 3year-olds in a genetic risk group of developing Alzheimer disease achieved lower scores on working memory and attention and also had smaller hippocampi than the non-risk group representatives [159].

CNS, central nervous system; DG, dentate gyrus; ESC, embryonic pluripotent stem cell; GO, Gene Ontology; HD, Huntington disease; HTT, huntingtin; iPSC, induced pluripotent stem cells; KO, knockout; MSN, medium spiny neuron; NPC, neural progenitor; NSC, neural stem cells; polyQ, polyglutamine; PSC, pluripotent stem cells; SVZ, subventricular zone; WT, wild type

Acknowledgements We express our gratitude to Pawel Goderski for correction of the manuscript for language and grammar.

Authors' contributions KW, W.J.S., M.T, and M. Figiel wrote the manuscript. All authors read and approved the final manuscript. K.W. performed all figures and meta-analysis. M. Figlerowicz critically revised the article. M. Figiel was responsible for obtaining funding.

\section{Compliance with Ethical Standards}

Funding This work was supported by a grant from the National Science Centre (grant number 2013/10/E/NZ4/00621) and the Polish Ministry of Science and Higher Education, under the KNOW program (01/KNOW2/2014). W.J.S. received support for young investigators from the Polish Ministry of Science and Higher Education (statutory funds). We express our gratitude to Pawel Goderski for correction of the manuscript for language and grammar.

Competing Interests The authors declare that they have no competing interests.

Open Access This article is distributed under the terms of the Creative Commons Attribution 4.0 International License (http:// creativecommons.org/licenses/by/4.0/), which permits unrestricted use, distribution, and reproduction in any medium, provided you give appropriate credit to the original author(s) and the source, provide a link to the Creative Commons license, and indicate if changes were made.

\section{References}

1. Paulsen JS, Long JD, Johnson HJ et al (2014) Clinical and Biomarker Changes in Premanifest Huntington Disease Show Trial Feasibility: A Decade of the PREDICT-HD Study. Front Aging Neurosci 6:78. doi:10.3389/fnagi.2014.00078

2. Quaid KA, Eberly SW, Kayson-Rubin E et al (2016) Factors related to genetic testing in adults at risk for Huntington disease: the prospective Huntington atrisk observational study (PHAROS). Clin Genet. doi:10.1111/cge.12893

3. Ciarochi JA, Calhoun VD, Lourens S et al (2016) Patterns of CoOccurring Gray Matter Concentration Loss across the Huntington Disease Prodrome. Front Neurol 7:147. doi:10.3389/fneur.2016. 00147

4. Epping EA, Kim J-I, Craufurd D et al (2016) Longitudinal Psychiatric Symptoms in Prodromal Huntington's Disease: A Decade of Data. Am J Psychiatry 173:184-192. doi:10.1176/ appi.ajp.2015.14121551

5. Harrington DL, Rubinov M, Durgerian S et al (2015) Network topology and functional connectivity disturbances precede the 
onset of Huntington's disease. Brain J Neurol 138:2332-2346. doi:10.1093/brain/awv145

6. Kim J-I, Long JD, Mills JA et al (2015) Performance of the 12item WHODAS 2.0 in prodromal Huntington disease. Eur J Hum Genet EJHG 23:1584-1587. doi:10.1038/ejhg.2015.11

7. Paulsen JS, Langbehn DR, Stout JC et al (2008) Detection of Huntington's disease decades before diagnosis: the Predict-HD study. J Neurol Neurosurg Psychiatry 79:874-880. doi:10.1136/ jnnp.2007.128728

8. Williams JK, Kim J-I, Downing N et al (2015) Everyday cognition in prodromal Huntington disease. Neuropsychology 29:255-267. doi:10.1037/neu0000102

9. Cummings DM, Milnerwood AJ, Dallérac GM et al (2006) Aberrant cortical synaptic plasticity and dopaminergic dysfunction in a mouse model of Huntington's disease. Hum Mol Genet 15:2856-2868. doi:10.1093/hmg/ddl224

10. Hodges A, Strand AD, Aragaki AK et al (2006) Regional and cellular gene expression changes in human Huntington's disease brain. Hum Mol Genet 15:965-977. doi:10.1093/hmg/dd1013

11. Kuhn A, Goldstein DR, Hodges A et al (2007) Mutant huntingtin's effects on striatal gene expression in mice recapitulate changes observed in human Huntington's disease brain and do not differ with mutant huntingtin length or wild-type huntingtin dosage. Hum Mol Genet 16:1845-1861. doi:10.1093/hmg/ddm133

12. Labadorf A, Hoss AG, Lagomarsino V et al (2015) RNA Sequence Analysis of Human Huntington Disease Brain Reveals an Extensive Increase in Inflammatory and Developmental Gene Expression. PloS One 10:e0143563. doi: 10.1371/journal.pone.0143563

13. Milnerwood AJ, Cummings DM, Dallérac GM et al (2006) Early development of aberrant synaptic plasticity in a mouse model of Huntington's disease. Hum Mol Genet 15:1690-1703. doi:10. 1093/hmg/dd1092

14. Schippling S, Schneider SA, Bhatia KP et al (2009) Abnormal motor cortex excitability in preclinical and very early Huntington's disease. Biol Psychiatry 65:959-965. doi:10.1016/ j.biopsych.2008.12.026

15. Lee JK, Mathews K, Schlaggar B et al (2012) Measures of growth in children at risk for Huntington disease. Neurology 79:668-674. doi:10.1212/WNL.0b013e3182648b65

16. Tereshchenko A, McHugh M, Lee JK et al (2015) Abnormal Weight and Body Mass Index in Children with Juvenile Huntington's Disease. J Huntingt Dis 4:231-238. doi:10.3233/ JHD-150152

17. Eatough V, Santini H, Eiser C et al (2013) The personal experience of parenting a child with Juvenile Huntington's Disease: perceptions across Europe. Eur J Hum Genet 21:1042-1048. doi:10. 1038/ejhg.2013.15

18. Squitieri F, Frati L, Ciarmiello A et al (2006) Juvenile Huntington's disease: does a dosage-effect pathogenic mechanism differ from the classical adult disease? Mech Ageing Dev 127:208-212. doi:10.1016/j.mad.2005.09.012

19. Lorincz MT, Zawistowski VA (2009) Expanded CAG repeats in the murine Huntington's disease gene increases neuronal differentiation of embryonic and neural stem cells. Mol Cell Neurosci 40: 1-13. doi:10.1016/j.mcn.2008.06.004

20. Niclis JC, Pinar A, Haynes JM et al (2013) Characterization of forebrain neurons derived from late-onset Huntington's disease human embryonic stem cell lines. Front Cell Neurosci 7:37. doi: $10.3389 /$ fncel.2013.00037

21. Nguyen GD, Molero AE, Gokhan S, Mehler MF (2013) Functions of huntingtin in germ layer specification and organogenesis. PloS One 8:e72698. doi:10.1371/journal.pone.0072698

22. Castiglioni V, Onorati M, Rochon C, Cattaneo E (2012) Induced pluripotent stem cell lines from Huntington's disease mice undergo neuronal differentiation while showing alterations in the lysosomal pathway. Neurobiol Dis 46:30-40. doi:10.1016/j.nbd. 2011.12.032

23. Camnasio S, Delli Carri A, Lombardo A et al (2012) The first reported generation of several induced pluripotent stem cell lines from homozygous and heterozygous Huntington's disease patients demonstrates mutation related enhanced lysosomal activity. Neurobiol Dis 46:41-51. doi:10.1016/j.nbd.2011.12.042

24. An MC, Zhang N, Scott G et al (2012) Genetic correction of Huntington's disease phenotypes in induced pluripotent stem cells. Cell Stem Cell 11:253-263. doi:10.1016/j.stem.2012.04. 026

25. Nekrasov ED, Vigont VA, Klyushnikov SA et al (2016) Manifestation of Huntington's disease pathology in human induced pluripotent stem cell-derived neurons. Mol Neurodegener 11:27. doi:10.1186/s13024-016-0092-5

26. HD iPSC Consortium (2012) Induced pluripotent stem cells from patients with Huntington's disease show CAG-repeat-expansionassociated phenotypes. Cell Stem Cell 11:264-278. doi:10.1016/j. stem.2012.04.027

27. Conforti P, Camnasio S, Mutti C et al (2013) Lack of huntingtin promotes neural stem cells differentiation into glial cells while neurons expressing huntingtin with expanded polyglutamine tracts undergo cell death. Neurobiol Dis 50:160-170. doi:10.1016/j.nbd. 2012.10.015

28. Ritch JJ, Valencia A, Alexander J et al (2012) Multiple phenotypes in Huntington disease mouse neural stem cells. Mol Cell Neurosci 50:70-81. doi:10.1016/j.mcn.2012.03.011

29. Nguyen GD, Gokhan S, Molero AE, Mehler MF (2013) Selective roles of normal and mutant huntingtin in neural induction and early neurogenesis. PloS One 8:e64368. doi:10.1371/journal. pone. 0064368

30. Mattis VB, Tom C, Akimov S et al (2015) HD iPSC-derived neural progenitors accumulate in culture and are susceptible to BDNF withdrawal due to glutamate toxicity. Hum Mol Genet 24:3257-3271. doi:10.1093/hmg/ddv080

31. Niclis JC, Trounson AO, Dottori M et al (2009) Human embryonic stem cell models of Huntington disease. Reprod Biomed Online 19:106-113

32. Biagioli M, Ferrari F, Mendenhall EM et al (2015) Htt CAG repeat expansion confers pleiotropic gains of mutant huntingtin function in chromatin regulation. Hum Mol Genet 24:2442-2457. doi:10. 1093/hmg/ddv006

33. Chiu F-L, Lin J-T, Chuang C-Y et al (2015) Elucidating the role of the $\mathrm{A} 2 \mathrm{~A}$ adenosine receptor in neurodegeneration using neurons derived from Huntington's disease iPSCs. Hum Mol Genet 24: 6066-6079. doi:10.1093/hmg/ddv318

34. McQuade LR, Balachandran A, Scott HA et al (2014) Proteomics of Huntington's disease-affected human embryonic stem cells reveals an evolving pathology involving mitochondrial dysfunction and metabolic disturbances. J Proteome Res 13:5648-5659. doi: 10.1021/pr500649m

35. Seriola A, Spits C, Simard JP et al (2011) Huntington's and myotonic dystrophy hESCs: down-regulated trinucleotide repeat instability and mismatch repair machinery expression upon differentiation. Hum Mol Genet 20:176-185. doi:10.1093/hmg/ddq456

36. Jonson I, Ougland R, Klungland A, Larsen E (2013) Oxidative stress causes DNA triplet expansion in Huntington's disease mouse embryonic stem cells. Stem Cell Res 11:1264-1271. doi: 10.1016/j.scr.2013.08.010

37. Lu B, Palacino J (2013) A novel human embryonic stem cellderived Huntington's disease neuronal model exhibits mutant huntingtin (mHTT) aggregates and soluble mHTT-dependent neurodegeneration. FASEB J Off Publ Fed Am Soc Exp Biol 27: 1820-1829. doi:10.1096/fj.12-219220

38. Jeon I, Lee N, Li J-Y et al (2012) Neuronal properties, in vivo effects, and pathology of a Huntington's disease patient-derived 
induced pluripotent stem cells. Stem Cells Dayt Ohio 30:20542062. doi:10.1002/stem.1135

39. Carter RL, Chen Y, Kunkanjanawan T et al (2014) Reversal of cellular phenotypes in neural cells derived from Huntington's disease monkey-induced pluripotent stem cells. Stem Cell Rep 3: 585-593. doi:10.1016/j.stemcr.2014.07.011

40. Jacobsen JC, Gregory GC, Woda JM et al (2011) HD CAG-correlated gene expression changes support a simple dominant gain of function. Hum Mol Genet 20:2846-2860. doi:10.1093/hmg/ ddr195

41. Ismailoglu I, Chen Q, Popowski M et al (2014) Huntingtin protein is essential for mitochondrial metabolism, bioenergetics and structure in murine embryonic stem cells. Dev Biol 391:230-240. doi: 10.1016/j.ydbio.2014.04.005

42. Ring KL, An MC, Zhang N et al (2015) Genomic Analysis Reveals Disruption of Striatal Neuronal Development and Therapeutic Targets in Human Huntington's Disease Neural Stem Cells. Stem Cell Rep 5:1023-1038. doi:10.1016/j.stemcr. 2015.11.005

43. Guo X, Disatnik M-H, Monbureau M et al (2013) Inhibition of mitochondrial fragmentation diminishes Huntington's disease-associated neurodegeneration. J Clin Invest 123:5371-5388. doi:10. 1172/JCI70911

44. Charbord J, Poydenot P, Bonnefond C et al (2013) High throughput screening for inhibitors of REST in neural derivatives of human embryonic stem cells reveals a chemical compound that promotes expression of neuronal genes. Stem Cells Dayt Ohio 31: 1816-1828. doi:10.1002/stem.1430

45. Lu X-H, Mattis VB, Wang N, et al (2014) Targeting ATM ameliorates mutant Huntingtin toxicity in cell and animal models of Huntington's disease. Sci Transl Med 6:268ra178. doi: 10.1126/ scitranslmed.3010523

46. Yao Y, Cui X, Al-Ramahi I et al (2015) A striatal-enriched intronic GPCR modulates huntingtin levels and toxicity. eLife. doi:10. 7554/eLife.05449

47. Chae J-I, Kim D-W, Lee N et al (2012) Quantitative proteomic analysis of induced pluripotent stem cells derived from a human Huntington's disease patient. Biochem J 446:359-371. doi:10. 1042/BJ20111495

48. Szlachcic WJ, Switonski PM, Krzyzosiak WJ, et al (2015) Huntington disease iPSCs show early molecular changes in intracellular signaling, the expression of oxidative stress proteins and the p53 pathway. Dis Model Mech 8:1047- 1057. doi: 10.1242/ dmm.019406

49. Duyao MP, Auerbach AB, Ryan A et al (1995) Inactivation of the mouse Huntington's disease gene homolog Hdh. Science 269: 407-410

50. Nasir J, Floresco SB, O'Kusky JR et al (1995) Targeted disruption of the Huntington's disease gene results in embryonic lethality and behavioral and morphological changes in heterozygotes. Cell 81: 811-823

51. Zeitlin S, Liu JP, Chapman DL et al (1995) Increased apoptosis and early embryonic lethality in mice nullizygous for the Huntington's disease gene homologue. Nat Genet 11:155-163. doi:10.1038/ng 1095-155

52. Woda JM, Calzonetti T, Hilditch-Maguire P et al (2005) Inactivation of the Huntington's disease gene (Hdh) impairs anterior streak formation and early patterning of the mouse embryo. BMC Dev Biol 5:17. doi:10.1186/1471-213X-5-17

53. Auerbach W, Hurlbert MS, Hilditch-Maguire P et al (2001) The HD mutation causes progressive lethal neurological disease in mice expressing reduced levels of huntingtin. Hum Mol Genet 10:2515-2523

54. White JK, Auerbach W, Duyao MP et al (1997) Huntingtin is required for neurogenesis and is not impaired by the
Huntington's disease CAG expansion. Nat Genet 17:404-410. doi:10.1038/ng1297-404

55. Arteaga-Bracho EE, Gulinello M, Winchester ML et al (2016) Postnatal and adult consequences of loss of huntingtin during development: Implications for Huntington's disease. Neurobiol Dis 96:144-155. doi:10.1016/j.nbd.2016.09.006

56. Molero AE, Arteaga-Bracho EE, Chen CH et al (2016) Selective expression of mutant huntingtin during development recapitulates characteristic features of Huntington's disease. Proc Natl Acad Sci U S A 113:5736-5741. doi:10.1073/pnas.1603871113

57. Dragatsis I, Levine MS, Zeitlin S (2000) Inactivation of Hdh in the brain and testis results in progressive neurodegeneration and sterility in mice. Nat Genet 26:300-306. doi:10.1038/81593

58. Kordasiewicz HB, Stanek LM, Wancewicz EV et al (2012) Sustained therapeutic reversal of Huntington's disease by transient repression of huntingtin synthesis. Neuron 74:1031-1044. doi:10. 1016/j.neuron.2012.05.009

59. Wang G, Liu X, Gaertig MA et al (2016) Ablation of huntingtin in adult neurons is nondeleterious but its depletion in young mice causes acute pancreatitis. Proc Natl Acad Sci U S A 113:33593364. doi:10.1073/pnas. 1524575113

60. Dietrich P, Shanmugasundaram R, Shuyu E, Dragatsis I (2009) Congenital hydrocephalus associated with abnormal subcommissural organ in mice lacking huntingtin in Wntl cell lineages. Hum Mol Genet 18:142-150. doi:10.1093/hmg/ddn324

61. Liu X, Wang C-E, Hong Y et al (2016) N-terminal Huntingtin Knock-In Mice: Implications of Removing the N-terminal Region of Huntingtin for Therapy. PLoS Genet 12:e1006083. doi:10.1371/journal.pgen.1006083

62. Neveklovska M, Clabough EBD, Steffan JS, Zeitlin SO (2012) Deletion of the huntingtin proline-rich region does not significantly affect normal huntingtin function in mice. J Huntingt Dis 1:7187. doi:10.3233/JHD-2012-120016

63. Zheng S, Clabough EBD, Sarkar S et al (2010) Deletion of the huntingtin polyglutamine stretch enhances neuronal autophagy and longevity in mice. PLoS Genet 6:e1000838. doi:10.1371/ journal.pgen.1000838

64. Grabel L (2012) Developmental origin of neural stem cells: the glial cell that could. Stem Cell Rev 8:577-585. doi:10.1007/ s12015-012-9349-8

65. Lo Sardo V, Zuccato C, Gaudenzi G et al (2012) An evolutionary recent neuroepithelial cell adhesion function of huntingtin implicates ADAM10- Ncadherin. Nat Neurosci 15:713-721. doi:10. 1038/nn.3080

66. Godin JD, Poizat G, Hickey MA et al (2010) Mutant huntingtinimpaired degradation of $\beta$-catenin causes neurotoxicity in Huntington's disease. EMBO J 29:2433-2445. doi:10.1038/ emboj.2010.117

67. Godin JD, Humbert S (2011) Mitotic spindle: focus on the function of huntingtin. Int J Biochem Cell Biol 43:852-856. doi:10. 1016/j.biocel.2011.03.009

68. Molina-Calavita M, Barnat M, Elias S et al (2014) Mutant huntingtin affects cortical progenitor cell division and development of the mouse neocortex. J Neurosci Off J Soc Neurosci 34: 10034-10040. doi:10.1523/JNEUROSCI.0715-14.2014

69. McKinstry SU, Karadeniz YB, Worthington AK et al (2014) Huntingtin is required for normal excitatory synapse development in cortical and striatal circuits. J Neurosci Off J Soc Neurosci 34: 9455-9472. doi:10.1523/JNEUROSCI.4699-13.2014

70. Molero AE, Gokhan S, Gonzalez S et al (2009) Impairment of developmental stem cell-mediated striatal neurogenesis and pluripotency genes in a knock-in model of Huntington's disease. Proc Natl Acad Sci U S A 106:21900-21905. doi:10.1073/pnas. 0912171106

71. Curtis MA, Penney EB, Pearson J et al (2005) The distribution of progenitor cells in the subependymal layer of the lateral ventricle 
in the normal and Huntington's disease human brain. Neuroscience 132:777-788. doi:10.1016/j.neuroscience.2004.12. 051

72. Takahashi K, Yamanaka S (2006) Induction of pluripotent stem cells from mouse embryonic and adult fibroblast cultures by defined factors. Cell 126:663-676. doi:10.1016/j.cell.2006.07.024

73. Laowtammathron C, Cheng EC, Cheng P-H et al (2010) Monkey hybrid stem cells develop cellular features of Huntington's disease. BMC Cell Biol 11:12. doi:10.1186/1471-2121-11-12

74. Putkhao K, Kocerha J, Cho I-K et al (2013) Pathogenic cellular phenotypes are germline transmissible in a transgenic primate model of Huntington's disease. Stem Cells Dev 22:1198-1205. doi:10.1089/scd.2012.0469

75. Verlinsky Y, Strelchenko N, Kukharenko V et al (2005) Human embryonic stem cell lines with genetic disorders. Reprod Biomed Online 10:105-110

76. Feyeux M, Bourgois-Rocha F, Redfern A et al (2012) Early transcriptional changes linked to naturally occurring Huntington's disease mutations in neural derivatives of human embryonic stem cells. Hum Mol Genet 21:3883-3895. doi:10.1093/hmg/dds216

77. Mateizel I, De Temmerman N, Ullmann U et al (2006) Derivation of human embryonic stem cell lines from embryos obtained after IVF and after PGD for monogenic disorders. Hum Reprod Oxf Engl 21:503-511. doi:10.1093/humrep/dei345

78. Drouet V, Ruiz M, Zala D et al (2014) Allele-specific silencing of mutant huntingtin in rodent brain and human stem cells. PloS One 9:e99341. doi:10.1371/journal.pone.0099341

79. Tropel P, Tournois J, Côme J et al (2010) High-efficiency derivation of human embryonic stem cell lines following pre-implantation genetic diagnosis. In Vitro Cell Dev Biol Anim 46:376-385. doi:10.1007/s11626-010-9300-8

80. Bradley CK, Scott HA, Chami O, et al (2011) Derivation of Huntington's disease-affected human embryonic stem cell lines. Stem Cells Dev 20:495- 502. doi: 10.1089/scd.2010.0120

81. Jacquet L, Neueder A, Földes G et al (2015) Three Huntington's Disease Specific Mutation-Carrying Human Embryonic Stem Cell Lines Have Stable Number of CAG Repeats upon In Vitro Differentiation into Cardiomyocytes. PloS One 10:e0126860. doi:10.1371/journal.pone. 0126860

82. Chan AWS, Cheng P-H, Neumann A, Yang J-J (2010) Reprogramming Huntington monkey skin cells into pluripotent stem cells. Cell Reprogramming 12:509-517. doi:10.1089/cell. 2010.0019

83. Park I-H, Arora N, Huo H et al (2008) Disease-specific induced pluripotent stem cells. Cell 134:877-886. doi:10.1016/j.cell.2008. 07.041

84. Cheng P-H, Li C-L, Chang Y-F et al (2013) miR-196a ameliorates phenotypes of Huntington disease in cell, transgenic mouse, and induced pluripotent stem cell models. Am J Hum Genet 93:306312. doi:10.1016/j.ajhg.2013.05.025

85. Juopperi TA, Kim WR, Chiang C-H et al (2012) Astrocytes generated from patient induced pluripotent stem cells recapitulate features of Huntington's disease patient cells. Mol Brain 5:17. doi:10. 1186/1756-6606-5-17

86. Tidball AM, Bryan MR, Uhouse MA et al (2015) A novel manganesedependent ATM-p53 signaling pathway is selectively impaired in patient-based neuroprogenitor and murine striatal models of Huntington's disease. Hum Mol Genet 24:1929 1944. doi:10.1093/hmg/ddu609

87. Tidball AM, Neely MD, Chamberlin R et al (2016) Genomic Instability Associated with p53 Knockdown in the Generation of Huntington's Disease Human Induced Pluripotent Stem Cells. PloS One 11:e0150372. doi:10.1371/journal.pone.0150372

88. Urbanek MO, Krzyzosiak WJ (2016) RNA FISH for detecting expanded repeats in human diseases. Methods San Diego Calif 98:115-123. doi:10.1016/j.ymeth.2015.11.017
89. Urbanek MO, Jazurek M, Switonski PM et al (2016) Nuclear speckles are detention centers for transcripts containing expanded CAG repeats. Biochim Biophys Acta 1862:1513-1520. doi:10. 1016/j.bbadis.2016.05.015

90. Rony IK, Baten A, Bloomfield JA et al (2015) Inducing pluripotency in vitro: recent advances and highlights in induced pluripotent stem cells generation and pluripotency reprogramming. Cell Prolif 48:140-156. doi:10.1111/cpr.12162

91. Genetic Modifiers of Huntington's Disease (GeM-HD) Consortium (2015) Identification of Genetic Factors that Modify Clinical Onset of Huntington's Disease. Cell 162:516-526. doi: 10.1016/j.cell.2015.07.003

92. Keum JW, Shin A, Gillis T et al (2016) The HTT CAG-Expansion Mutation Determines Age at Death but Not Disease Duration in Huntington Disease. Am J Hum Genet 98:287-298. doi:10.1016/ j.ajhg.2015.12.018

93. Smith A (2017) Formative pluripotency: the executive phase in a developmental continuum. Dev Camb Engl 144:365-373. doi:10. 1242/dev.142679

94. Teslaa T, Teitell MA (2015) Pluripotent stem cell energy metabolism: an update. EMBO J 34:138-153. doi: 10.15252/ embj.201490446

95. Ma H, Morey R, O’Neil RC et al (2014) Abnormalities in human pluripotent cells due to reprogramming mechanisms. Nature 511: 177-183. doi:10.1038/nature13551

96. Wutz A (2012) Epigenetic alterations in human pluripotent stem cells: a tale of two cultures. Cell Stem Cell 11:9-15. doi:10.1016/j. stem.2012.06.012

97. Liang G, Zhang Y (2013) Genetic and epigenetic variations in iPSCs: potential causes and implications for application. Cell Stem Cell 13:149-159. doi:10.1016/j.stem.2013.07.001

98. Cai L, Hayes NL, Nowakowski RS (1997) Synchrony of clonal cell proliferation and contiguity of clonally related cells: production of mosaicism in the ventricular zone of developing mouse neocortex. J Neurosci Off J Soc Neurosci 17:2088-2100

99. Karus M, Blaess S, Brüstle O (2014) Self-organization of neural tissue architectures from pluripotent stem cells. J Comp Neurol 522:2831-2844. doi:10.1002/cne.23608

100. Conti L, Cattaneo E (2010) Neural stem cell systems: physiological players or in vitro entities? Nat Rev Neurosci 11:176-187. doi:10.1038/nrn2761

101. Metzler M, Chen N, Helgason CD et al (1999) Life without huntingtin: normal differentiation into functional neurons. J Neurochem 72:1009-1018

102. Conti L, Pollard SM, Gorba T et al (2005) Niche-independent symmetrical selfrenewal of a mammalian tissue stem cell. PLoS Biol 3:e283. doi:10.1371/journal.pbio.0030283

103. Wild EJ, Tabrizi SJ (2014) Targets for future clinical trials in Huntington's disease: What's in the pipeline? Mov Disord 29: 1434-1445. doi:10.1002/mds.26007

104. Bath KG, Akins MR, Lee FS (2012) BDNF control of adult SVZ neurogenesis. Dev Psychobiol 54:578-589. doi:10.1002/dev. 20546

105. Spiliotopoulos D, Goffredo D, Conti L et al (2009) An optimized experimental strategy for efficient conversion of embryonic stem (ES)-derived mouse neural stem (NS) cells into a nearly homogeneous mature neuronal population. Neurobiol Dis 34:320-331. doi:10.1016/j.nbd.2009.02.007

106. Usdin K, House NCM, Freudenreich CH (2015) Repeat instability during DNA repair: Insights from model systems. Crit Rev Biochem Mol Biol 50:142-167. doi:10.3109/10409238.2014. 999192

107. McMurray CT (2010) Mechanisms of trinucleotide repeat instability during human development. Nat Rev Genet 11:786-799. doi: $10.1038 / \operatorname{nrg} 2828$ 
108. Shelbourne PF, Keller-McGandy C, Bi WL et al (2007) Triplet repeat mutation length gains correlate with cell-type specific vulnerability in Huntington disease brain. Hum Mol Genet 16:11331142. doi: $10.1093 / \mathrm{hmg} / \mathrm{ddm} 054$

109. Budworth H, Harris FR, Williams P et al (2015) Suppression of Somatic Expansion Delays the Onset of Pathophysiology in a Mouse Model of Huntington's Disease. PLoS Genet 11: e1005267. doi:10.1371/journal.pgen.1005267

110. Wyles SP, Brandt EB, Nelson TJ (2014) Stem cells: the pursuit of genomic stability. Int J Mol Sci 15:20948-20967. doi:10.3390/ ijms 151120948

111. Weissbein U, Benvenisty N, Ben-David U (2014) Quality control: Genome maintenance in pluripotent stem cells. J Cell Biol 204: 153-163. doi:10.1083/jcb.201310135

112. Ruiz S, Lopez-Contreras AJ, Gabut M et al (2015) Limiting replication stress during somatic cell reprogramming reduces genomic instability in induced pluripotent stem cells. Nat Commun 6: 8036. doi:10.1038/ncomms9036

113. Marques Sousa C, Humbert S (2013) Huntingtin: here, there, everywhere! J Huntingt Dis 2:395-403. doi:10.3233/JHD-130082

114. Bhide PG, Day M, Sapp E et al (1996) Expression of normal and mutant huntingtin in the developing brain. J Neurosci Off J Soc Neurosci 16:5523-5535

115. Ruzo A, Ismailoglu I, Popowski M et al (2015) Discovery of novel isoforms of huntingtin reveals a new hominid-specific exon. PloS One 10:e0127687. doi:10.1371/journal.pone.0127687

116. Hughes AC, Mort M, Elliston L et al (2014) Identification of novel alternative splicing events in the huntingtin gene and assessment of the functional consequences using structural protein homology modelling. J Mol Biol 426:1428-1438. doi:10.1016/j.jmb.2013. 12.028

117. Lin B, Nasir J, MacDonald H et al (1994) Sequence of the murine Huntington disease gene: evidence for conservation, alternate splicing and polymorphism in a triplet (CCG) repeat [corrected]. Hum Mol Genet 3:85-92

118. Sathasivam K, Neueder A, Gipson TA et al (2013) Aberrant splicing of HTT generates the pathogenic exon 1 protein in Huntington disease. Proc Natl Acad Sci U S A 110:2366-2370. doi:10.1073/ pnas. 1221891110

119. Arrasate M, Finkbeiner S (2012) Protein aggregates in Huntington's disease. Exp Neurol 238:1-11. doi:10.1016/j. expneurol.2011.12.013

120. Hoffner G, Djian P (2014) Monomeric, oligomeric and polymeric proteins in huntington disease and other diseases of polyglutamine expansion. Brain Sci 4:91-122. doi:10.3390/brainsci4010091

121. Kamburov A, Stelzl U, Lehrach H, Herwig R (2013) The ConsensusPathDB interaction database: 2013 update. Nucleic Acids Res 41:D793-D800. doi:10.1093/nar/gks1055

122. R Core Team (2016) R: A language and environment for statistical computing. R Foundation for Statistical Computing

123. Warnes G, Bolker B, Bonebakker L Gplots: Various R Programming Tools for Plotting Data. R package version 3.0.1

124. Ellrichmann G, Reick C, Saft C, Linker RA (2013) The role of the immune system in Huntington's disease. Clin Dev Immunol 2013: 541259. doi: $10.1155 / 2013 / 541259$

125. Bowles KR, Jones L (2014) Kinase signalling in Huntington's disease. J Huntingt Dis 3:89-123. doi:10.3233/JHD-140106

126. Basson MA (2012) Signaling in cell differentiation and morphogenesis. Cold Spring Harb Perspect Biol. doi:10.1101/ cshperspect.a008151

127. Molchadsky A, Rivlin N, Brosh R et al (2010) p53 is balancing development, differentiation and de-differentiation to assure cancer prevention. Carcinogenesis 31:1501-1508. doi:10.1093/ carcin/bgq101
128. Tedeschi A, Di Giovanni S (2009) The non-apoptotic role of p53 in neuronal biology: enlightening the dark side of the moon. EMBO Rep 10:576-583. doi:10.1038/embor.2009.89

129. Marine J-C, Francoz S, Maetens M et al (2006) Keeping p53 in check: essential and synergistic functions of Mdm2 and Mdm4. Cell Death Differ 13:927-934. doi:10.1038/sj.cdd.4401912

130. Van Nostrand JL, Brady CA, Jung H et al (2014) Inappropriate p53 activation during development induces features of CHARGE syndrome. Nature 514:228-232. doi:10.1038/nature13585

131. Ryan AB, Zeitlin SO, Scrable H (2006) Genetic interaction between expanded murine Hdh alleles and p53 reveal deleterious effects of p53 on Huntington's disease pathogenesis. Neurobiol Dis 24:419-427. doi:10.1016/j.nbd.2006.08.002

132. Brustovetsky N (2016) Mutant Huntingtin and Elusive Defects in Oxidative Metabolism and Mitochondrial Calcium Handling. Mol Neurobiol 53:2944-2953. doi:10.1007/s12035-015-9188-0

133. Guedes-Dias P, Pinho BR, Soares TR et al (2016) Mitochondrial dynamics and quality control in Huntington's disease. Neurobiol Dis 90:51-57. doi:10.1016/j.nbd.2015.09.008

134. Mochel F, Haller RG (2011) Energy deficit in Huntington disease: why it matters. J Clin Invest 121:493-499. doi:10.1172/JCI45691

135. Uittenbogaard M, Chiaramello A (2014) Mitochondrial biogenesis: a therapeutic target for neurodevelopmental disorders and neurodegenerative diseases. Curr Pharm Des 20:5574-5593

136. Ying Q-L, Wray J, Nichols J et al (2008) The ground state of embryonic stem cell self-renewal. Nature 453:519-523. doi:10. 1038/nature06968

137. Leoni V, Caccia C (2015) The impairment of cholesterol metabolism in Huntington disease. Biochim Biophys Acta 1851:10951105. doi:10.1016/j.bbalip.2014.12.018

138. Kumar A, Ratan RR (2016) Oxidative Stress and Huntington's Disease: The Good, The Bad, and The Ugly. J Huntingt Dis 5: 217-237. doi:10.3233/JHD-160205

139. Bigarella CL, Liang R, Ghaffari S (2014) Stem cells and the impact of ROS signaling. Dev Camb Engl 141:4206-4218. doi:10. 1242/dev.107086

140. Prentice H, Modi JP, Wu J-Y (2015) Mechanisms of Neuronal Protection against Excitotoxicity, Endoplasmic Reticulum Stress, and Mitochondrial Dysfunction in Stroke and Neurodegenerative Diseases. Oxid Med Cell Longev 2015:964518. doi:10.1155/ 2015/964518

141. Zuccato C, Valenza M, Cattaneo E (2010) Molecular mechanisms and potential therapeutical targets in Huntington's disease. Physiol Rev 90:905-981. doi:10.1152/physrev.00041.2009

142. Hale AN, Ledbetter DJ, Gawriluk TR, Rucker EB (2013) Autophagy: regulation and role in development. Autophagy 9: 951-972. doi:10.4161/auto.24273

143. Guan J-L, Simon AK, Prescott M et al (2013) Autophagy in stem cells. Autophagy 9:830-849. doi:10.4161/auto.24132

144. Martin DDO, Ladha S, Ehrnhoefer DE, Hayden MR (2015) Autophagy in Huntington disease and huntingtin in autophagy. Trends Neurosci 38:26-35. doi:10.1016/j.tins.2014.09.003

145. Cortes CJ, La Spada AR (2014) The many faces of autophagy dysfunction in Huntington's disease: from mechanism to therapy. Drug Discov Today 19:963-971. doi:10.1016/j.drudis.2014.02. 014

146. Kalathur RKR, Giner-Lamia J, Machado S et al (2015) The unfolded protein response and its potential role in Huntington's disease elucidated by a systems biology approach. F1000Research 4: 103. doi:10.12688/f1000research.6358.2

147. Hermel E, Gafni J, Propp SS et al (2004) Specific caspase interactions and amplification are involved in selective neuronal vulnerability in Huntington's disease. Cell Death Differ 11:424-438. doi:10.1038/sj.cdd.4401358

148. Tong Y, Ha TJ, Liu L et al (2011) Spatial and temporal requirements for huntingtin $(\mathrm{Htt})$ in neuronal migration and survival 
during brain development. J Neurosci Off J Soc Neurosci 31: 14794-14799. doi:10.1523/JNEUROSCI.2774-11.2011

149. Graham RK, Deng Y, Slow EJ et al (2006) Cleavage at the caspase- 6 site is required for neuronal dysfunction and degeneration due to mutant huntingtin. Cell 125:1179-1191. doi:10.1016/j.cell. 2006.04.026

150. Rigamonti D, Bauer JH, De-Fraja C et al (2000) Wild-type huntingtin protects from apoptosis upstream of caspase-3. J Neurosci Off J Soc Neurosci 20:3705-3713

151. Zhang Y, Leavitt BR, van Raamsdonk JM et al (2006) Huntingtin inhibits caspase-3 activation. EMBO J 25:5896-5906. doi:10. 1038/sj.emboj.7601445

152. Kiechle T, Dedeoglu A, Kubilus J et al (2002) Cytochrome C and caspase-9 expression in Huntington's disease. Neuromolecular Med 1:183-195. doi:10.1385/NMM:1:3:183

153. Squitieri F, Maglione V, Orobello S (1996) Fornai F (2011) Genotype-, agingdependent abnormal caspase activity in Huntington disease blood cells. J Neural Transm Vienna Austria 118:1599-1607. doi:10.1007/s00702-011-0646-1
154. Hirano S, Takeichi M (2012) Cadherins in brain morphogenesis and wiring. Physiol Rev 92:597-634. doi:10.1152/physrev.00014. 2011

155. Kawauchi T (2015) Cellullar insights into cerebral cortical development: focusing on the locomotion mode of neuronal migration. Front Cell Neurosci 9:394. doi:10.3389/fncel.2015.00394

156. Reis SA, Thompson MN, Lee J-M et al (2011) Striatal neurons expressing fulllength mutant huntingtin exhibit decreased $\mathrm{N}$ cadherin and altered neuritogenesis. Hum Mol Genet 20:2344 2355. doi:10.1093/hmg/ddr127

157. Studer L, Vera E, Cornacchia D (2015) Programming and Reprogramming Cellular Age in the Era of Induced Pluripotency. Cell Stem Cell 16:591-600. doi:10.1016/j.stem. 2015.05.004

158. Tousley A, Kegel-Gleason KB Induced Pluripotent Stem Cells in Huntington's Disease Research: Progress and Opportunity. J Huntingt Dis 5:99-131. doi:10.3233/JHD-160199

159. Chang L, Douet V, Bloss C et al (2016) Gray matter maturation and cognition in children with different APOE $\varepsilon$ genotypes. Neurology 87:585-594. doi:10.1212/WNL.0000000000002939 